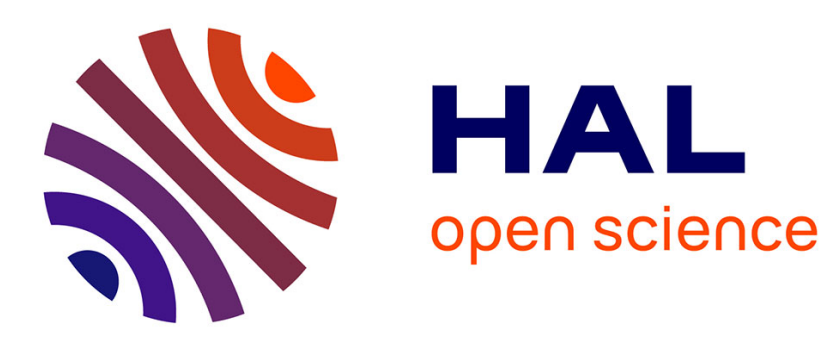

\title{
Interactions of metal ions with chitosan-based sorbents: a review \\ Guibal Eric
}

\section{To cite this version:}

Guibal Eric. Interactions of metal ions with chitosan-based sorbents: a review. Separation and Purification Technology, 2004, 38 (1), pp.43-74. 10.1016/j.seppur.2003.10.004 . hal-03015915

\section{HAL Id: hal-03015915 https://hal.mines-ales.fr/hal-03015915}

Submitted on 20 Nov 2020

HAL is a multi-disciplinary open access archive for the deposit and dissemination of scientific research documents, whether they are published or not. The documents may come from teaching and research institutions in France or abroad, or from public or private research centers.
L'archive ouverte pluridisciplinaire HAL, est destinée au dépôt et à la diffusion de documents scientifiques de niveau recherche, publiés ou non, émanant des établissements d'enseignement et de recherche français ou étrangers, des laboratoires publics ou privés. 


\title{
Interactions of metal ions with chitosan-based sorbents: a review
}

\author{
Eric Guibal \\ Ecole des Mines d'Alès, Laboratoire Génie de l'Environnement Industriel, 6 Avenue de Clavières, F-30319 Ales Cedex, France
}

\begin{abstract}
Metal cations can be adsorbed by chelation on amine groups of chitosan in near neutral solutions. In the case of metal anions, the sorption proceeds by electrostatic attraction on protonated amine groups in acidic solutions. However, the presence of ligands and the $\mathrm{pH}$ strongly control sorption performance (sorption isotherm) and the uptake mechanism (changing the speciation of the metal may result in turning the chelation mechanism into the electrostatic attraction mechanism). Several examples are discussed with precious metals $(\mathrm{Pd}, \mathrm{Pt})$, oxo-anions $(\mathrm{Mo}, \mathrm{V})$ and heavy metals $(\mathrm{Cu}, \mathrm{Ag})$. Sorption performance (equilibrium uptake but also kinetics) is also strictly controlled by other structural parameters of the polymer (degree of deacetylation, crystallinity for example) that control swelling and diffusion properties of chitosan. The identification of the limiting steps of the sorption process helps in designing new derivatives of chitosan. Diffusion properties may be improved by physical modification of chitosan (manufacturing gel beads, decreasing crystallinity). Selectivity can be enhanced by chemical modification (grafting, for example, sulfur compounds). Several examples are discussed to demonstrate the versatility of the material. This versatility allows the polymer to be used under different forms (from water soluble form, to solid form, gels, fibers, hollow fibers ....) for polymer-enhanced ultrafiltration and sorption processes. These interactions of metal ions with chitosan can be used for the decontamination of effluents, for the recovery of valuable metals but also for the development of new materials or new processes involving metal-loaded chitosan. Several examples are cited in the design of new sorbing materials, the development of chitosan-supported catalysts, the manufacturing of new materials for opto-electronic applications or agriculture (plant disease treatment....).
\end{abstract}

Keywords: Chitosan; Ultrafiltration; Sorption; Kinetics; Isotherms; Diffusion

\section{Introduction}

The increasing demand for new and economic processes for the recovery of metal ions from industrial effluents has led many research groups to investigate the possibility of using waste biomaterials for metal uptake $[1,2]$. Biosorption consists in using materials

\footnotetext{
* Tel.: +33-466782734; fax: +33-466782701.

E-mail address: eric.guibal@ema.fr (E. Guibal).
}

of biological origin, more specifically living or dead microorganisms, to accumulate solute on the surface of the sorbent. Fungal biomass has been widely studied, undoubtedly due to the fact that these microorganisms are commonly used for the production of industrial enzymes. After enzyme extraction (generally, endocellular or parietal enzymes recovered after cell wall disruption), the biomass must be eliminated, since the cell becomes inactive for further production of enzymes. These sorbents have been efficiently 
used for the uptake of a great variety of metal ions [3]. However, these materials are not very appropriate for the treatment of industrial effluents using column systems, for example, due to clogging effects. In addition, preconditioning is frequently required, using agglomeration procedures, for example, to control hydrodynamic properties, at the expense of a significant loss in sorption efficiency. Moreover, high metal sorption properties have been directly correlated to the composition of cell walls. The location of metal sorption on the constituents of cell walls has been characterized by transmission electron microscopy [4,5]. One of the most representative polymers in fungal cell walls is chitin [6]. Chitin is a polymer made up of acetylglucosamine units. In the case of some Mucorales species, chitin is replaced by chitosan, a polymer made up of glucosamine units. This has motivated research into the use of chitin/chitosan material for the uptake of metal ions [7-11]. These sorption properties have been used for environmental purposes (removal of toxic metals) [9,12-17], separation processes (recovery of valuable metals in hydrometallurgy) [18], and also for analytical purposes (as a pre-concentration step before using conventional spectrophotometric or spectroscopic analysis) [19-24].

Chitosan is obtained on an industrial scale by the alkaline deacetylation of chitin, one of the most abundant biopolymers in nature. The main commercial sources of chitin are crab and shrimp shells, though other sources such as fungal biomass, insect cuticle or squid pen may be used [25]. The principal parameters that can be used for the characterization of chitosan are the fraction of deacetylation, the polymer weight and the crystallinity. These parameters significantly influence its physico-chemical properties. The fraction of deacetylation for commercial chitosan samples is usually lower than $95 \%$. Higher deacetylation degree may be achieved at the expense of supplementary deacetylation steps, which contribute to partial depolymerization, and high costs when appropriate and sophisticated processes are employed for deacetylation. Highly deacetylated products are generally reserved for biomedical applications. The presence of acetylglucosamine and glucosamine units contributes to the existence of heterogeneities in the polymer. Amine groups are strongly reactive with metal ions. Indeed, nitrogen atoms hold free electron doublets that can react with metal cations. Amine groups are thus responsible for the uptake of metal cations by a chelation mechanism. However, the amine groups are easily protonated in acidic solutions. Hence, the protonation of these amine groups may cause electrostatic attraction of anionic compounds, including metal anions (resulting from metal chelation by chloride, anionic ligands, etc.), or anionic dyes [26-29].

Chitosan can easily be modified by chemical or physical processes to prepare chitosan derivatives (obtained by grafting new functional groups) or to condition the polymer (by preparation of membranes, gel beads, fibers, hollow fibers). These processes may be used for controlling the reactivity of the polymer (improving the affinity of the sorbent for the metal, changing the selectivity series for sorption, changing the $\mathrm{pH}$ range for optimum sorption) or enhancing sorption kinetics (controlling diffusion properties, for example). The possibility of dissolving chitosan in acidic solutions may be used for polymer-enhanced ultrafiltration: chitosan reacts with metal ions, and the macro-ligand loaded with metal ions is retained by the ultrafiltration membrane.

Despite a large number of studies on the use of chitosan for metal ion recovery for the last twenty years, this research area fails to find practical application at the industrial scale. This may be explained by several parameters: (a) the cost of the raw material compared to synthetic polymers and resins (about US\$ 10-15); (b) the variability in the characteristics of material (that can rebut industrial users); (c) the availability of the resource (that is controlled by the demand at the commercial level: the polymer fails at the moment to find an attractive market that would allow expending the production). However, the information provided by these studies open the route for new applications of chitosan for the preparation of new materials for other applications that could be more money-making than environmental applications. The last section of the paper shows some new applications of metal-loaded chitosan. These different points will be discussed in detail in the following sections before concluding with the possible use of metal-loaded sorbents for other environmental applications: sorption of organic molecules (pesticides), catalytic applications (oxidation, reduction, degradation of organic contaminants) or preparation of new materials. 

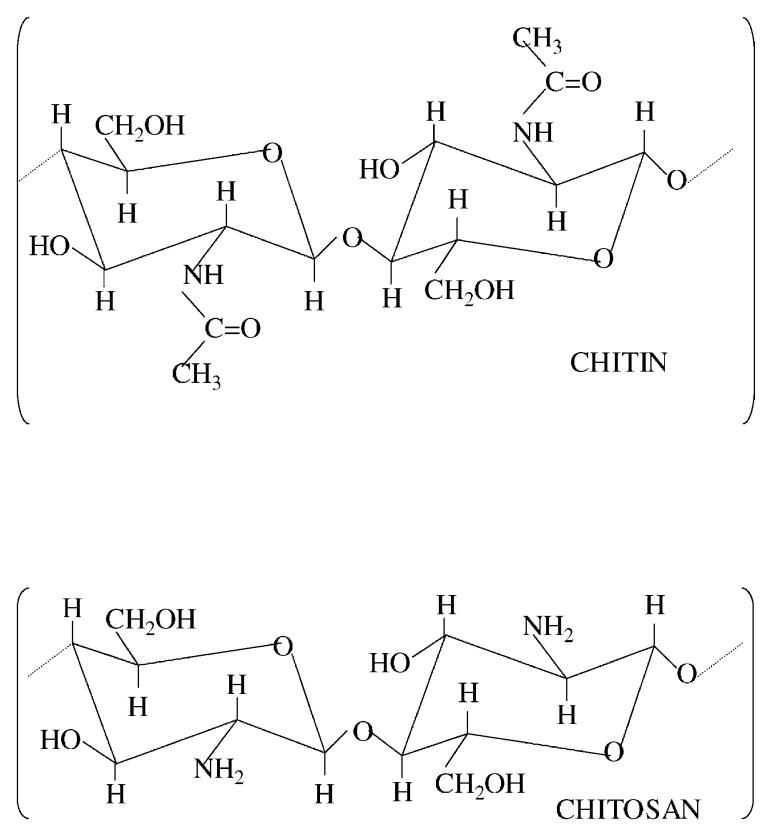

Fig. 1. Structure of chitin and chitosan units.

\section{Chitosan-based sorbents: structure and sorption properties}

\subsection{Raw chitosan}

The principal characteristics of chitosan that may affect its sorption properties are its deacetylation degree, crystallinity and, to a lesser extent, molecular weight. The deacetylation degree controls the fraction of free amine groups that will be available for interactions with metal ions. The amine groups on chitosan are much more reactive than the acetamide groups on chitin [30-35]. The free electron doublet of nitrogen on amine groups is responsible for the sorption of metal cations. The protonation of amine groups in acidic solutions is responsible for the electrostatic attraction of metal anions. The fraction of free amine groups is thus a key parameter. In fact, both chitin and chitosan are made up of glucosamine and acetylglucosamine units (Fig. 1), the only generally accepted criterion for qualifying these materials refers to the solubility of the polymer in acidic solutions, and the polymer is usually called chitosan when it is soluble in acidic solutions, which corresponds to a deacetylation degree greater than $60 \%$ [25]. There are many different methods for evaluating the degree of deacetylation; the most common being infra-red spectroscopy and NMR analysis [36-39].

Actually, rather than the fraction or number of free amine groups available for metal uptake, it would be better to consider the number of accessible-free amine groups. Indeed, the total number of free amine groups is not necessarily accessible to metal uptake. Some of these amine sites are involved in hydrogen bonds (intra- or intermolecular bonds). Moreover, the residual crystallinity of the polymer may control the accessibility to sorption sites. The origin of chitin influences the arrangement of polymer chains, and 3 different types of chitin have been identified: $\alpha$-chitin (shrimp and crab shells), $\beta$-chitin (squid pen) and $\gamma$-chitin (stomach cuticles of cephalopoda), corresponding to parallel, anti-parallel, and alternated arrangements of polymer chains, respectively. After extraction, or dissolving of the polymer, the crystallinity of the material is modified and the different types of crystallinity cited for chitin disappear, important modifications in the crystallinity of the polymer are observed as a result of interactions of chitosan with metal ions or acids [40,41]. The crystallinity of the polymer is measured by X-ray diffraction considering the ratio of the surface area of the crystalline zone to the total surface area of the spectrum (corrected by the baseline) [42]. The most convenient processes for decreasing polymer crystallinity consist in dissolving the chitosan (in acid solutions) followed by either a coagulation process (for the preparation of gel beads) [43-45], or direct freeze-drying of the polymer solution [46,47].

The solubility of chitosan is also an important parameter, which can be controlled by the polymer weight, the type and concentration of the acid used for dissolving the polymer, and the presence of metal ions in the solution, which can interact with chitosan to cross-link polymer chains and decrease its solubility. Though chitosan is soluble in most mineral and organic acids, it is relatively stable in sulfuric acid solutions. This parameter has to be taken into account for the design of the experimental mode (adsorption versus ultrafiltration) and for the chemical modification of the polymer (a cross-linking treatment may be required). This may also be of great importance for metal desorption from loaded sorbent. The sorption of metal cations usually occurs at $\mathrm{pH}$ close to neutral and the desorption is usually carried out by contact 
with acidic solution [48], though chelating agents can be used.

\subsection{Chitosan modification}

\subsubsection{Physical modifications}

One of the most interesting advantages of chitosan is its versatility. The material can readily be modified physically, preparing differently conditioned polymer forms such as powder, nano particles [49], gel beads [43,44,50-53], membranes [54-56], sponge [57,58], honeycomb [59], fibers [28,60] or hollow fibers $[61,62]$ for varied fields of application (waste water treatment, biomedical, textiles, etc.).

The control of polymer conditioning may be helpful for designing the sorption process. Therefore, ion exchange resins are commonly operated in fixed-bed systems. Due to resistance to intraparticle mass transfer in raw chitosan, it is usually necessary to use very small particles to improve sorption kinetics. However, small particles have proved to be inappropriate for use in column systems since they cause column clogging and serious hydrodynamic limitations. Using chitosan gel beads may be an alternative since it improves both diffusion properties and hydrodynamic behavior, at the expense of a decrease in volumetric sorption capacities (due to the high water-content of the beads). The drying of the beads to improve volumetric sorption capacities leads to a significant decrease in kinetic properties (diffusion limitations). It has been observed that the controlled drying of the beads, proceeding by saturation of the beads with a spacer-a non-reactive compound such as saccharose-prior to drying prevents the structure from collapsing during water removal. The beads partially regain their initial volume and maintain their kinetic performance for the sorption of precious metals [63]. In the case of membrane preparation, the acetic acid-chitosan solution is typically poured on a Petri dish and, after the solvent has evaporated, the membrane is neutralized with sodium hydroxide. In fact, the kinetic performance and accessibility to internal sites are limited [54], possibly due to the change in diffusion properties of the polymer after the drying step. A controlled drying procedure would improve sorbent efficiency, using freeze-drying or the spacer-inclusion technique to prevent structure collapse. Fibrous materials should be more efficient since the coagulation process used for fiber prepara- tion allows the wet state to be maintained throughout the extrusion process, which prevents the collapse of the structure.

Some dual physical and chemical modifications have been performed for improving metal sorption selectivity by template formation or the imprinting method [64-68]. The target metal is adsorbed in the first part of the process (or mixed with chitosan solution) prior to the chemical modification, which may consist of a chemical grafting or cross-linking step. Finally, in a third step, the target metal is removed by desorption. The preliminary sorption of the target metal (or a metal with a similar ionic radius) prevents the interaction of the cross-linking agent with the sorption site and preserves a cavity tailored to the volumetric space of the target metal for further sorption operation. This treatment increases the sorption capacity of chitosan for rhodium, copper and gallium.

\subsubsection{Chemical modifications}

The ability of chitosan to be chemically modified is well documented and the reader is referred to two comprehensive reviews by Roberts [25] and Kurita [69]. This brief review will focus on chitosan derivatives tailored for metal ion sorption. The chemical modification of chitosan may be justified by two objectives: (a) preventing the dissolving of the polymer when metal sorption is performed in acidic solutions (or when metal desorption occurs in acidic media), or (b) improving metal sorption properties (increase of sorption capacities or enhancement of sorption selectivity) [25,70-74].

The cross-linking procedure may be performed by reaction of chitosan with different cross-linking agents (bi-functional reagents) such as glutaraldehyde $[25,68$, 74-79], 1,1,3,3-tetramethoxypropane [80], oxidized $\beta$-cyclodextrin ( $\beta$-cyclodextrin polyaldehyde) $[81,82]$, ethyleneglycol diglycidyl ether [83-86] or glycerolpolyglycidylether [65] or hexamethylenediisocyanate [87]. It is also possible to use mono-functional reagents epichlorhydrin (or chloromethyloxirane), which may react, on the one hand, by opening the ether group for grafting an amine function through Schiff's base reaction, while the chloride group may then interact on other functional groups or other amine sites [88]. Tri-polyphosphate has also been selected as a possible cross-linking agent, which can be used for the preparation of chitosan gel beads 
by the coagulation/neutralization effect [89-91]. The cross-linking step may cause a significant decrease in metal uptake efficiency and sorption capacities, especially in the case of chemical reactions involving amine groups. For example, the reaction of chitosan amine groups with glutaraldehyde leads to the formation of imine functions (which can finally be hydrogenated using sodium borohydride). The reaction leads to a decrease in the number of amine groups, resulting in a decrease in sorption capacity, especially in the case of metal ions sorbed through chelation mechanisms $[33,76]$. However, this limiting effect of chemical cross-linking with glutaraldehyde, for example, significantly depends on the procedure used. Indeed, Kurita et al. in a series of papers in the late seventies discussed the effect of glutaraldehyde cross-linking on copper sorption for sorbents prepared by heterogeneous and homogeneous cross-linking [92,93]. In the first case, chitosan (solid state) was mixed with glutaraldehyde solution, while in the latter case chitosan was mixed with glutaraldehyde solution after being dissolved in acetic acid. An optimum aldehyde/amine ratio was found for copper and mercury sorption, which depended on the cross-linking operation mode (water-soluble or solid-sate chitosan). The initial increase in metal ion adsorption was attributed to the low levels of cross-linking in the precipitates preventing the formation of closely packed chain arrangements without any great reduction in the swelling capacity. At higher levels of cross-linking the precipitates had lower swelling capacities, and hence lower accessibilities, because of the more extensive three-dimensional network and also its more hydrophobic character with increased glutaraldehyde content [25]. On the other hand, when an ion exchange mechanism is involved in metal uptake, cross-linking has a significantly lower influence on metal sorption capacities [94].

A great number of chitosan derivatives have been obtained by grafting new functional groups on the chitosan backbone. There are several reasons for grafting new functional groups: (a) to increase the density of sorption sites, (b) to change the $\mathrm{pH}$ range for metal sorption, (c) to change the sorption sites and/or the uptake mechanism in order to increase sorption selectivity for the target metal.

In the case of chitosan gel beads, the high water content of the beads leads to poor volumetric density of sorption sites and the grafting of new amine groups may compensate for this drawback: poly(ethylenimine) has been successfully grafted on chitosan via different processes using for example glutaraldehyde [95], hexamethylene diisocyanate [87,96,97], epichlorhydrin $[83,85,86]$ as the linker/spacer agent. Usually, the sorption behavior of the derivatives follows the same trend as raw chitosan: the acid-base properties of the derivative material may simply shift the optimum $\mathrm{pH}$ range for metal sorption.

The grafting of carboxylic functions has frequently been regarded as an interesting process for increasing the sorption properties of chitosan $[98,99]$. Carboxymethyl-chitin and -chitosan have been prepared by reaction of chitin/chitosan with chloroacetic acid in a suitable solvent (propanol for example) [100-104]. Carboxylic acids have also been grafted on chitosan through Schiff's base reactions [105-111]. Usually, the aim of these modifications is to design chelating derivatives for the sorption of metal cations $[100,105-107,109]$. Another way to achieve the grafting of carbonyl and carboxylic functions may consist in reacting chitosan with carboxylic anhydrides $[112,113]$. Recently, a great deal of attention has been paid to the grafting of crown ether on chitosan for manufacturing new metal ion sorbents, once again using a Schiff's base reaction [114-116].

Inoue and his group have developed a number of chitosan derivatives bearing carboxylic and amine groups by grafting ethylene diamine tetra acetic acid (EDTA), diethylenetriaminepentaacetic acid (DTPA) (by reaction of the corresponding organic acid anhydride with amine groups of chitosan), imino diacetic acid (IDA) functions (by reaction of chitosan with glyconitrile, followed by an alkaline hydrolysis reaction) [18,117-120]. The reactions are relatively complex and it appears that their use will certainly be limited to the sorption of precious metals. A Schiff's base reaction was used for the grafting of methylpyridine on chitosan in order to prepare a sorbent for precious metal recovery [121], and also for copper uptake [122]. Kang et al. prepared prepared amidoximated composites of chitosan and poly(acrylonitrile) for the recovery of metal cations [123].

Several phosphorus derivatives of chitosan have also been synthesized by (a) grafting phosphate [124-127] by reaction of phosphorus pentoxide or phosphorus oxychloride in a suitable solvent (water-free), (b) grafting phosphonic acid by the Mannich reaction 
$[128,129]$. Despite the interesting sorption properties of phosphorylated derivatives of chitosan, their use for metal ion sorption is limited due to (a) their solubility in water (in most cases) and (b) the affinity of these derivatives for alkaline and alkaline-earth metals. This affinity for these metals may lead to strong competition for the recovery of heavy metals in industrial effluents. Their solubility requires the use of ultrafiltration process for the recovery of loaded complexes, or the cross-linking of the soluble product at the expense of a possible loss of sorption capacity (decrease in the number of available sorption sites).

The grafting of sulfur compounds on chitosan has been the subject of many studies for the design of chelating chitosan-based resins [95,100,130-136]. Different strategies have been used for the preparation of these derivatives, using (a) direct reaction with carbon sulfur to prepare dithiocarbamate chitosan [133,137], (b) direct reaction with mercapto acetic acid [134], or (c) the grafting of thiourea (or dithiooxamide) via a cross-linking agent (such as glutaraldehyde [132,135], or epichlorhydrin, followed by hydrolysis of the intermediary isothiouronium compound) [130,134]. Other sulfur derivatives bearing chloride reactive groups together with sulfur groups (for example chloromethyl thiirane) can also be used [131]. Becket et al prepared a sulfur derivative by a two step procedure consisting of pre-reaction of chitosan with glutaraldehyde (and reduction by sodium cyanoborohydride) followed by reaction with a mixture of formaldehyde and thioglycolic acid [74]. These sulfur derivatives have been successfully tested for the recovery of mercury and the uptake of precious metals, owing to the chelating affinity of sulfur compounds for metal ions.

Sulfonic groups have been also grafted on chitosan to improve sorption capacity for metal ions in acidic solutions $[138,139]$.

\section{Interaction mechanisms}

Despite the large number of papers dedicated to the sorption of metal ions, most of them focus on the evaluation of sorption performances and only a few of them aim at gaining a better understanding of sorption mechanisms. However, it is accepted that amine sites are the main reactive groups for metal ions, though hydroxyl groups (especially in the C-3 position) may contribute to sorption. These reactive groups may interact with metal ions through different mechanisms depending on the metal, the $\mathrm{pH}$, and the matrix of the solution. The free electron doublet on nitrogen may bind metal cations at $\mathrm{pH}$ close to neutrality (or weak acidity) [140-143]. On the other hand, the protonation of amine groups in acidic solutions gives the polymer a cationic behavior and consequently the potential for attracting metal anions [144-146].

It is important to observe that the sorption of a metal may involve different mechanisms (chelation versus electrostatic attraction) depending on the composition of the solution, the $\mathrm{pH}$, since these parameters may affect the protonation of the polymer (repulsion of metal cations) and the speciation of metal ions. The chelation of metal cations by ligands in solution may result in the formation of metal anions, which therefore turns the chelation mechanism on chitosan to an electrostatic attraction mechanism on protonated amine groups of the polymer. This effect of metal speciation on sorption mechanism and uptake performance is discussed in detail in Section 5.

\subsection{Chelation}

The theory of hard and soft acids and bases (HSB), as defined by Pearson [147], describes the ability of ions to interact or enter into coordinate bonding with other ions or with ligands and shows that this depends on the availability of their outermost electrons and empty molecular orbitals. This must be considered on top of any electrostatic effects due to ion-ion, ion-dipole, and ion-higher multipole interactions. The last type of effect is governed primarily by the charge and size of the ion. The first type of effect can be described by means of the softness parameters and the Lewis acid/base parameters of the ions [148]. The HSAB concept provides a description of the capacities of ions to prefer ligands of the same kind (soft-soft and hard-hard) to those of different kinds when forming coordinative bonds. Softness of ions generally goes hand in hand with their polarizability, and hardness with their electrostatic field strength.

Most studies of the chelation mechanisms involved in the sorption of metal ions by chitosan have focused on the uptake of copper. Several contradictory hypotheses have been proposed for the interpretation of 
uptake mechanisms. They can be generally classified in two groups: (a) the "bridge model" and (b) the "pendant model". In the "bridge model", metal ions are bound with several amine groups from the same chain or from different chains, via inter- or intramolecular complexation [54,149-151], as opposed to the "pendant model", in which the metal ion is bound to an amine group in a pendant fashion [40,152-154]. Several techniques have been used to investigate these interaction mechanisms including circular dichroism [153], UV spectrophotometry [150], infra-red spectrometry [8], Mossbauer spectrometry [155], electrospray mass spectrometry [156], potentiometry $[150,151,153,157]$ and calorimetric titration [32].

Domard [153] pointed out that chitosan forms a unique complex with copper, whose structure is close to $\left[\mathrm{Cu} \mathrm{NH} \mathrm{NH}_{2}(\mathrm{OH})_{2}\right]$ below pH 6.1. Considering the coordination sphere of copper, the fourth site can be occupied by either a water molecule or the $\mathrm{OH}$ group in C-3 position. Monteiro and Airoldi [32] recently confirmed this hypothesis by calorimetric measurements. Copper bonds to three oxygen atoms and one nitrogen atom, with square-planar or tetrahedral geometry.

Many of these studies observed differences in the sorption mechanisms and/or metal species adsorbed on the polymer when the experimental conditions are altered $(\mathrm{pH}$, metal concentration, metal/ligand ratio) [54,150,156]. For example, Rhazi et al. [150] found that the coordination number (ligand-metal molar ratio) varied from 1 at $\mathrm{pH} 5.3$ to 2 at $\mathrm{pH} 5.8$. The change in the conformation of the polymer (dissolved sate, solid state ... ) may be a cause of a change in the coordination mechanism and more specifically the kind of complex formed between copper and amine groups. Most of the studies were performed with chitosan solutions using oligomers or polymers and it was generally concluded that the monomer (glucosamine unit) is not very efficient at complexing copper. Oligomers proved more efficient, though the minimum degree of polymerization required for efficient sorption varies according to the author. Shahgoli et al. [156] observed strong chelation of copper with chitosan tetrasaccharide, while Rhazi et al. [150] found that that the threshold value for the polymerization degree was 6 . The need for polymerization is another piece of evidence for the contribution of several glucosamine units in the sequestration mechanism, undoubtedly due to the contribution of hydroxyl groups of vicinal units together with amine groups of a given monomer.

Few studies have been published on the interpretation of the chelation mechanisms of chitosan with other metals. Hirano et al. [158] described the formation of a 1:1 complex between the amine groups of chitosan and uranyl ions: elemental analysis obtained a U/N ratio close to 1. Piron and Domard [159] found that uranium is adsorbed on chitosan in a pendant mode by reaction of amine groups with uranyl divalent cations together with $2 \mathrm{OH}$ groups, the fourth site being occupied by either a water molecule or the $\mathrm{OH}$ group in C-3 position in the glucosamine unit. On the other hand, the correlation of optimum sorption with experimental conditions corresponding to the predominance of hydrolyzed uranyl species $\left(\left(\mathrm{UO}_{2}\right)_{3}(\mathrm{OH})_{5}{ }^{+}\right)$ has been used for identifying these hydrolyzed species as the adsorbable species $[8,160]$. The large size of this species may introduce diffusion limitations but the sorption of 1 polymer unit corresponds to the sorption of 3 uranyl units, which may explain the high sorption capacities reached with this ion.

A first attempt at using molecular mechanical modeling has recently been made in order to correlate experimental sorption data to chelation mechanisms for the sorption of lead and mercury using chitosan and pectic acid $[161,162]$. The authors arrive at contrasting conclusions, showing the difficulty of using simple models for the interpretation of the interactions of these polymeric materials with metals. They conclude that several sorption sites may be involved in the sorption of these metal cations, complementary studies seem to be necessary in order to obtain a better insight into the sorption mechanisms. Similarly debatable conclusions have been reached using density functional theory for the interpretation of copper and nickel sorption on chitosan: Braier and Jishi [163] proposed a model whereby the sorption of metal ions takes place in the vicinity of the glycosidic oxygen with contributions from nitrogen and $\mathrm{OH}$ groups, but these hypotheses are not supported by gas phase mass spectrometry [156].

It is interesting to observe that chitosan has very limited affinity for alkaline and alkaline-earth metals due to the absence of $d$ and $f$ unsaturated orbitals (unlike transition metals) [51]. Therefore, chitosan is selective of transition metals over common non-transition metals. However, these metal ions can be sorbed on 
chitosan derivatives when phosphorylated groups are grafted on the polymer [124-128].

\subsection{Ion exchange/electrostatic attraction}

The protonation of amine functions in acid solutions is controlled by the $\mathrm{p} K_{\mathrm{a}}$ of the polymer, which in turn is controlled by the degree of deacetylation (DA) of the chitosan and by its charge density. Hence, it depends on the extent of neutralization of charged groups, according to Katchalsky's equation [25]. Sorlier et al. [164] extensively studied the acid-base properties of chitosan in function of the degree of acetylation and the dissociation degree. They observed that the $\mathrm{p} K_{\mathrm{a}}$ varies drastically with these parameters: between 6.3 and 7.2 at complete dissociation, corresponding to the intrinsic dissociation constant $\mathrm{p} K_{0}$ (for DA ranging between 5 and $75 \%$ ), while the change in the $\mathrm{p} K_{\mathrm{a}}$ between extreme DA values considerably increases when the dissociation degree decreases. These properties are key parameters for the understanding of the electrostatic properties of chitosan and its cationic behavior, which in turn may influence its ability to bind anions through electrostatic attraction.

A number of studies have focused on the sorption of metal anions and anionic dyes on chitosan and derivative materials. At neutral $\mathrm{pH}$, about $50 \%$ of total amine groups remain protonated and theoretically available for the sorption of metal anions. However, the existence of free amine groups may cause direct chelation of metal cations (which may co-exist with anionic species, depending on the speciation of the metal). As the $\mathrm{pH}$ decreases, the protonation of amine groups increases, together with the efficiency. The distribution coefficient $\left(D, 1 \mathrm{~kg}^{-1}\right)$ can be defined as the ratio of sorption capacity $q$ (concentration of the metal on the sorbent, $\mathrm{mg} \mathrm{g}^{-1}$ ) to the equilibrium concentration of the metal in the solution $\left(C_{\mathrm{eq}}, \mathrm{mgl}^{-1}\right)$. Usually the logarithm of the distribution coefficient can be plotted versus the $\mathrm{pH}$ and the slope of the curve can be used to determine the stoichiometry of ion exchange (the amount of metal adsorbed per mole of protonated amine groups) [117]. Actually, in most cases, with raw chitosan, the distribution coefficient reaches a maximum before it decreases at low $\mathrm{pH}$. This decrease may be explained by a strong competitor effect of the anions brought about by the dissociation of the acid used for $\mathrm{pH}$ control, or present in the matrix of the solution. The optimum $\mathrm{pH}$ is frequently found around pH 2-4 [44,45,79,94,136,165-168]. Below this limit value, usually a large excess of competitor anions limits sorption efficiency. This competitor effect is the subject of many studies aiming to develop chitosan derivatives that are less sensitive to the presence of competitor anions $[95,132,135,136]$.

This electrostatic attraction may occur by direct interaction with free metal anions, but that mechanism may be also involved in the sorption of metal complexes, as a result of the interaction of metal cations with ligands in the solution [52,84-86,169]. Actually, the formation of complexes, with ligands and/or $\mathrm{OH}^{-}$ influences the speciation of metals ions and thus the sorption efficiency and uptake mechanism.

This property of electrostatic interaction between protonated amine groups and anions has been used for the gelation of chitosan [170-174]. For example, in the case of molybdate, polynuclear species may interact with several amine groups from the same chain or different chains, strengthening the structure of the polymer and preventing it from dissolving in moderate acidic solutions. Polyoxoanions and polyphosphate anions are very efficient for the formation of these multiple bonds $[91,166]$.

XPS analysis has been used to determine the oxidation state of metal ions after sorption on chitosan and it appears that the polymer is able to reduce sorbed metal [175]. The reducing activity strongly depends (a) on the oxidation potential of the metal (correlated to the normal redox potential scale), and (b) the structure of the polymer (glutaraldehyde cross-linking significantly increases the reducing effect). Chromate was almost completely reduced on the sorbent, while molybdate was only partially reduced, particularly on the external surface of chitosan beads due to a combined effect of the reducing ends and of polymer chains and a photochemical effect. This photo-reduction effect has also been observed in the case of uranium on raw chitosan [176]. The difference in potential was measured between two compartments containing uranyl solutions and chitosan connected by a conducting agar bridge. The difference in potential became significant when one of the compartments was submitted to ultra-violet irradiation. Bubbling air through the compartment decreased the photo-reduction effect due to the re-oxidation effect of the oxygen. The reducing effect of chitosan, 
completed by a photochemical effect, is not very strong but cannot be neglected.

\subsection{Uptake by formation of ternary complexes}

Since alkaline and alkaline-earth metals are not significantly sorbed on raw chitosan, it is necessary to graft phosphate or phosphonic groups on the chitosan backbone [124-128]. Another possibility was recently developed by Domard's group for the uptake of calcium and strontium on raw chitosan $[177,178]$. The mechanism involves the formation of a ternary complex between calcium, chitosan and sodium undecylenate. One calcium ion is involved in the formation of an ion pair with two carboxylate groups of undecylenate before the ion pair complexes with the amine groups of chitosan [177]. They found that the interaction is significantly weaker than that involved in coordination mechanisms. Piron et al. [178] developed a similar approach for the uptake of ${ }^{85} \mathrm{Sr}$, a $\gamma$ emitter, found in waste streams from nuclear power plants. While strontium was not adsorbed on chitosan, the addition of carbonate led to the sorption of strontium. Experiments performed at different ionic strengths confirmed that the interaction was not based on an electrostatic attraction mechanism, and the interaction of $-\mathrm{NH}_{2}$ groups with $\left(\mathrm{Sr}^{2+}, \mathrm{CO}_{3}{ }^{2-}\right)$ ion pairs appeared the most probable mechanism.

\section{Evaluation of sorption performance}

Evaluation of sorption performance and the usability of a specified sorbent for the treatment of metal-bearing solutions must take into account the following parameters: sorption isotherms, uptake kinetics, uptake selectivity (and effect of competitor ions) and finally the possibility of desorbing the metals for recovery and the recycling of the sorbent.

\subsection{Sorption isotherms}

Sorption isotherms plot the sorption capacity, $q$, versus the residual concentration of the metal in the solution at equilibrium $\left(C_{\mathrm{eq}}\right)$. This equilibrium distribution of the adsorbate (the metal ion) between the solid and the liquid phase is obtained by varying the symmetrical experimental parameters (initial metal concentra- tion, $C_{0}$; the volume of solution, $V$; and the sorbent mass, $m$ ). The residual concentration of the metal in the solution is used to calculate the sorption capacity by the mass balance equation: $q=\left(C_{0}-C_{\text {eq }}\right) V / m$. Readers interested in a detailed discussion of sorption isotherms should refer to the comprehensive reference works by Tien [179] and McKay et al. [180]. The most frequently used equations for describing sorption isotherms are the Langmuir, Freundlich and Langmuir-Freundlich equations given below:

Langmuir model:

$q=\frac{q_{\mathrm{m}} b C_{\mathrm{eq}}}{1+b C_{\mathrm{eq}}}$

Feundlich model:

$q=k C_{\mathrm{eq}}^{1 / n}$

Langmuir-Freundlich model:

$q=\frac{q_{\mathrm{m}} b C_{\mathrm{eq}}^{1 / n}}{1+b C_{\mathrm{eq}}^{1 / n}}$

where $q_{\mathrm{m}}\left(\mathrm{mg} \mathrm{g}^{-1}\right.$ or $\left.\mathrm{mmolg}^{-1}\right), b\left(1 \mathrm{mg}^{-1}\right.$ or $\left.1 \mathrm{mmol}^{-1}\right), k\left(\mathrm{mg}^{1-1 / n} \mathrm{~g}^{-1} \mathrm{l}^{1 / n}\right.$, or $\mathrm{mmol}^{1-1 / n} \mathrm{~g}^{-1}$ $1^{1 / n}$ ), $n$ (dimensionless) are the parameters of the different models, corresponding to the maximum sorption capacity at saturation of the monolayer, the affinity of the sorbent for the target metal, and the constants of the Freundlich model, respectively. The Redlich-Peterson equation only differs from the Langmuir-Freundlich equation by the absence of exponent on $C_{\mathrm{eq}}$ at the numerator part of the equation [181].

The parameters of the models can be obtained by suitable linearization procedures followed by regression analysis. Alternatively, non-linear regression analysis, included in most mathematical analysis software packages (Mathematica ${ }^{\circledR}$, for example), can be used for the direct determination of model parameters. Kinniburgh [182] showed that non-linear regression gives a more accurate determination of model parameters than linearization/linear regression methods.

However, an important criterion should be highlighted: these models, initially developed for the modeling of gas and organic adsorbates, are based on the hypothesis of physical sorption; in the case of ion adsorption, which is more chemical than physical, it would be more appropriate to consider ion adsorption 
with models based on chemical reactions, or complexation models. In order to approach more accurately the real phenomena involved in metal ion uptake it would be necessary to take into account the surface charge of the sorbent and to develop theoretical concepts based on Gouy-Chapman theory [179]. However, when designing the surface complexation model, the problem may be encountered that it is not possible experimentally to identify the exact nature of all relevant surface complexes present on a solid surface $[179,183-186]$. These concepts are very sophisticated and usually require simplification (kind of complexes, surface charge and structure). They have rarely been used for describing metal ion sorption on chitosan. Gonzalez-Davila and Millero [187] used a simplified approach based on surface charge for the modeling of copper on chitin and observed that the basic equation is mathematically and conceptually equivalent to the Langmuir isotherm at a given $\mathrm{pH}$. The $\mathrm{pH}$ is an important parameter, which will be discussed later, and even the simplified models such as Langmuir and Freundlich can only be used in solutions whose $\mathrm{pH}$ remains constant (or is maintained constant) throughout the sorption procedure. This is a point that is frequently underestimated and many papers do not report the effect on the sorption isotherm of $\mathrm{pH}$ variation during sorption. Recently, some efforts have been made to develop new models taking into account the effect of $\mathrm{pH}$ on the isotherm profile [188-191]. Pagnanelli et al. [191] obtained sorption isotherms at different $\mathrm{pHs}$ for different metals and observed that the maximum sorption capacity was directly correlated to the logarithmic value of the first hydrolysis constant of the metal. They determined the variation law of maximum sorption capacity versus $\mathrm{pH}$ and then introduced this function in the Langmuir equation. They discuss the effect of $\mathrm{pH}$ on maximum sorption capacity for the different metals in function of the acid/base properties of these metals and notice that the impact may be controlled by the sorption mechanism involved at a given metal concentration. They comment that at low metal concentration, the adsorbate is sorbed through highly specific interactions, while at high metal concentration the saturation of these specific sites leads to an increased contribution from the ion exchange mechanism. Other studies focusing on the effect of $\mathrm{pH}$ on sorption isotherms have been developed based on multi-component adsorption, the proton being one of these compo- nents [190], the so-called extended (or competitive) Langmuir model. In this case, it is necessary to use non-linear regression analysis to fit experimental data [190]:

$q=\frac{q_{\mathrm{m}} b C_{\mathrm{eq}}}{1+b C_{\mathrm{eq}}+b b_{\mathrm{H}} C_{\mathrm{eq}, \mathrm{H}}}$

where $b_{\mathrm{H}}$ is the Langmuir apparent dissociation constant for protons, and $C_{\mathrm{eq}, \mathrm{H}}$ is the equilibrium concentration of protons in the solution, other parameters refer to metal species. It should be noticed that these parameters (for the metal) in the standard Langmuir equation are $\mathrm{pH}$-dependent and are actually only valid for one particular $\mathrm{pH}$ value. The extended Langmuir model (also called competitive Langmuir model) takes differences in $\mathrm{pH}$ into account. Parameters can be obtained by non-linear regression analysis. Obviously, in the case of multi-component solutions, residual concentrations and sorption capacities could be given in molar units. The Langmuir-Freundlich equation could also be modified to take into account the effect of proton competition; in this case, the respective residual (metal and proton) concentrations would be affected by the corresponding exponent [190].

Juang and Shao [189] proposed an alternative method using the mass balance equations and the mass action law. It is important in this case to know the stoichiometry of the complex ligand-metal (or to vary its value to fit the equation to experimental data). Several studies of poly-oxoanions have shown that chitosan has a marked preference for polynuclear species [166,167]; and it was possible to fit experimental data using the Langmuir equation but under restrictive conditions, using the concentration of adsorbable (polynuclear) species instead of total metal concentration [166].

The sorption of metals in multi-component solutions continues to attract a great deal of attention and the reference book written by Tien [179] is a source of comprehensive information on the models and the way to solve them.

It is also important to note that in certain cases, for a given concentration range the sorption capacity may vary linearly with residual concentration (linear isotherm, similar to Henry's law). In some (rare) cases, corresponding to irreversible (or rectangular) isotherms, the sorption capacity reaches a maximum 
(a plateau) at very low residual concentration and can be considered approximately constant.

\subsection{Uptake kinetics}

The uptake of adsorbates by the sorbent from solutions involves several steps that transfer the solute from the bulk of the liquid phase to the specific sites inside the particles as well as steps in the adsorption process itself. Transportation of the adsorbate includes several steps such as external diffusion and intraparticle diffusion. Mixing the solution sufficiently (providing homogeneous distribution of the solute and the adsorbate in the solution) limits the influence of mass transfer resistance to film diffusion. In the case of physical adsorption, the adsorption itself can be considered to be an instantaneous step and the kinetics to be mainly controlled by mass transfer resistance to intraparticle diffusion. In the case of chemical reactions, their own kinetic rates may interfere in the control of the sorption rate [179]. For a complete modeling of sorption kinetics it would be necessary to take into account not only these diffusion equations, derived from Fick's laws, but also boundary conditions, including the sorption isotherm equation that controls the equilibrium at the solid-liquid interface and the reaction kinetic equation, when necessary. This means that the system of equations is very complex and cannot generally be solved analytically (except with simplified hypotheses corresponding to irreversible and linear isotherms). The problem can therefore only be solved by numerical analysis $[45,179,192]$. Alternatively, it is possible to simplify the solving method by separating diffusion steps (film and intraparticle diffusion) or taking into account only diffusion steps in the control of kinetic rates $[44,86,91,109,190,192-196]$. These approaches are clearly less accurate but they are also easier and provide approximate values for the kinetic coefficients. It is true that these conventional models are also difficult to transfer to the chitosan flake material, whose shape (tablets rather than spheres) and porosity (weak porosity) are very different from conventional materials. This is another reason justifying the use of simple models for rough evaluation of kinetic parameters.

In the case of a reaction controlled by resistance to film diffusion, which may occur within the first minutes of contact between the solution and the sorbent, the film mass transfer rate $\left(k_{\mathrm{F}} \times A_{\mathrm{sp}}\right)$ can be roughly estimated according to [165]:

$$
\begin{aligned}
\frac{C(t)}{C_{0}}= & \frac{1}{1+\left(m q_{\mathrm{m}} b / V\right)}+\frac{m q_{\mathrm{m}} b}{V+m q_{\mathrm{m}} b} \\
& \times \exp \left(-\frac{V+m q_{\mathrm{m}} b}{m q_{\mathrm{m}} b} k_{\mathrm{F}} A_{\mathrm{sp}} t\right)
\end{aligned}
$$

where $k_{\mathrm{F}}$ is the external film diffusion coefficient $\left(\mathrm{m} \mathrm{s}^{-1}\right)$ and $A_{\mathrm{sp}}$ is the specific surface area $\left(\mathrm{m}^{2} \mathrm{~m}^{-3}\right.$, exchange surface area per volume of solution) given by [197]:

$S=\frac{6 m}{d_{\mathrm{p}} V \rho(1-\varepsilon)}$

where $d_{\mathrm{p}}$ is the diameter of the particles $(\mathrm{m}), \rho$ the density of the sorbent $\left(\mathrm{kg} \mathrm{m}^{-3}\right)$ and $\varepsilon$ is the porosity of sorbent particles. Alternatively, it is possible to obtain an approximation for the value of the external film diffusion coefficient using the correlation equations $[33,179,198,199]$. It should be noted that in most cases in batch systems the external diffusion weakly affects the overall sorption kinetics (providing that agitation is sufficient); while in column systems the film resistance can play an important role in the control of mass transfer, especially when trace levels of metal ions are considered since it is not easy to control agitation inside the column (it depends on flow rate and distribution of sorbent particles).

In the case of a reaction controlled only by intraparticle diffusion, the equations given by Crank [200] can be used (Table 1) [44,190]. It is also possible to describe diffusion according to (a) the homogeneous diffusion model (HDM) controlled by film diffusion (FD) or particle diffusion (PD) and the shrinking core model (SCM) controlled by film diffusion, particle diffusion, or chemical reaction (CR). To check the controlling step it is also possible to linearize specific functions of a designated variable (specific to the model) (Table 2): a linear fit of experimental data is indicative of the mechanism involved in kinetic control $[86,165]$. Ho et al. review various complementary kinetic models [201].

Alternatively, the kinetics can be described by a second order equation, under different hypotheses such as reversible and irreversible reactions [190]:

Reversible reaction:

$\mathrm{S}+\mathrm{Me} \stackrel{k_{1}, k_{-1}}{\leftrightarrow} \mathrm{S}-\mathrm{Me}$ 
Table 1

Equations for the simplified modeling of intraparticle diffusion equation for flakes and beads (FATE, fractional approach to equilibrium; $\beta_{i}$, non-zero roots of the parametric equation; $\alpha$, fractional uptake at equilibrium) [200] (d and 1 are particle diameter and thickness of the flakes, respectively)

\begin{tabular}{lll}
\hline & Flakes/Slab & Beads \\
\hline FATE & $\frac{M_{t}}{M_{\infty}}=1-\sum_{i=1}^{\infty} \frac{2 \alpha(1+\alpha)}{1+\alpha+\alpha^{2} \beta_{i}^{2}} \exp \left(-\frac{\beta_{i}^{2} D t}{l^{2}}\right)$ & $\frac{M_{t}}{M_{\infty}}=1-\sum_{i=1}^{\infty} \frac{6 \alpha(1+\alpha)}{9+9 \alpha+\alpha^{2} \beta_{i}^{2}} \exp \left(-\frac{\beta_{i}^{2} D t}{d^{2}}\right)$ \\
$\beta_{\mathrm{i}}$ & $\tan \beta_{i}=-\alpha \beta_{i}$ & $\tan \beta_{i}=\frac{3 \beta_{i}}{3+\alpha \beta_{i}^{2}}$ \\
$\alpha$ & $\frac{M_{\infty}}{V C_{0}}=\frac{C_{0}-C_{\mathrm{eq}}}{C_{0}}=\frac{1}{1+\alpha}$ & $\frac{M_{\infty}}{V C_{0}}=\frac{C_{0}-C_{e q}}{C_{0}}=\frac{1}{1+\alpha}$ \\
\hline
\end{tabular}

Table 2

Linearization of kinetic data-simplified equations for ionexchange mechanisms using homogeneous diffusion model (HDM) and shrinking core model (SCM) with film diffusion (FD), particle diffusion (PD) and chemical reaction $(\mathrm{CR})$ control $(X)$ represents the fractional approach to equilibrium

\begin{tabular}{lll}
\hline $\begin{array}{l}\text { Model and } \\
\text { controlling } \\
\text { step }\end{array}$ & $F(X)(y$-axis $)$ & $\begin{array}{l}\text { Time } \\
\text { parameter } \\
(x \text {-axis })\end{array}$ \\
\hline HDM-FD & $-\ln (1-X)$ & $t$ \\
HDM-PD & $-\ln \left(1-X^{2}\right)$ & $t$ \\
SCM-FD & $X$ & $\int_{0}^{t} C(t) \mathrm{d} t$ \\
SCM-PD & $3-3(1-X)^{2 / 3}-2 X$ & $\int_{0}^{t} C(t) \mathrm{d} t$ \\
SCM-CR & $1-(1-X)^{1 / 3}$ & $\int_{0}^{t} C(t) \mathrm{d} t$ \\
\hline
\end{tabular}

Irreversible reaction:

$\mathrm{S}+\mathrm{Me} \stackrel{k_{2}}{\rightarrow} \mathrm{S}-\mathrm{Me}$

where $\mathrm{S}$ is the sorption site and Me the metal ion, $k_{1}$ and $k_{-1}$ are respectively the second-order forward and first-order reverse rate constants for the reversible reaction; and $k_{2}$ the second-order rate constant for the irreversible reaction. The reactions can be described by the equation shown in Table 3 (presented together with the solutions given by Chu [190]).

Lenhart et al. [202] used the surface complexation model coupled with the mass transfer resistance equation to simulate the sorption of uranyl ions by chitin and proposed two sets of equations depending on the type of sorption system (batch reactor or continuously stirred tank reactor).

\subsection{Selectivity and competitor effects}

Only a limited number of studies have been carried out on the sorption of metals in multi-component solutions using chitosan, and, generally, these studies were performed in experimental conditions that do not really allow the selectivity of the sorption to be determined. Indeed, the precipitation phenomena that may occur under different $\mathrm{pH}$ and concentration ranges for the different metals can lead to misunderstandings and inaccurate interpretation of sorption phenomena. Moreover, the comparison of sorption performance would require a full study at different $\mathrm{pHs}$ corresponding to the optimum $\mathrm{pHs}$ for sorption of the different

Table 3

Solutions of reversible and irreversible second order equation

\begin{tabular}{lll}
\hline & Reversible & Irreversible \\
\hline Equation & $\frac{\mathrm{d} q(t)}{\mathrm{d} t}=k_{1} C(t)\left(q_{\mathrm{m}}-q(t)\right)-k_{-1} q(t)$ & $\frac{\mathrm{d} C(t)}{\mathrm{d} t}=-k_{2} C(t)\left(C(t)-C_{\mathrm{eq}}^{*}\right)$ \\
Solution & $\frac{C(t)}{C_{0}}=1-\frac{m}{V C_{0}} \frac{(c+a)\left[1-\exp \left(-2 a(m / V) k_{1} t\right)\right]}{\left[((c+a) /(c-a))-\exp \left(-2 a(m / V) k_{1} t\right)\right]}$ & $\frac{C(t)}{C_{0}}=\frac{C_{\mathrm{eq}}^{*}}{C_{0}-\left[\left(C_{0}-C_{\mathrm{eq}}^{*}\right) \exp \left(-C_{\mathrm{eq}}^{*} k_{2} t\right)\right]}$ \\
Parameter & $a^{2}=c^{2}-C_{0} q_{\mathrm{m}}\left(\frac{V}{m}\right)$ & $C_{\mathrm{eq}}^{*}=\frac{-h+\sqrt{h^{2}+4\left(C_{0} / b\right)}}{2}$ \\
Parameter & $c=0.5\left(C_{0} \frac{V}{m}+q_{\mathrm{m}}+\frac{V}{b m}\right)$ & $h=\frac{1}{b}-C_{0}+q_{\mathrm{m}} \frac{m}{V}$ \\
\hline
\end{tabular}

NB: In the irreversible second equation, when the equilibrium relationship of the adsorption system is of the Langmuir form, $C_{\text {eq }}$ is given by $C_{\mathrm{eq}}^{*}$ (defined in the table), other isotherm parameters are defined from Eq. (1) and mass balance equation. 
metals before a well-established conclusion could be reached. Roberts [25] reports and compares results obtained by several groups and concludes that sorption selectivity varies strongly with experimental conditions (excess of metal versus chitosan). There is still a need for an in-deep study of sorption selectivity in order to explain these discrepancies.

Understanding the different mechanisms involved in metal sequestration enables the possibility of separating metals from mixtures to be anticipated. For example, in acidic solutions chitosan protonation enables adsorption of metal anions but significantly reduces the affinity of the sorbent for the uptake of metal cations. Hence, metal anions (precious metal ions, for example) can be recovered selectively from transition metals (base metals). Generally, except in the case of formation of ternary complexes, chitosan has no affinity for alkaline and alkaline-earth metals, therefore it is possible to separate transition metals from these background metals.

The presence of anions (chloride, nitrate ...) in excess can significantly decrease the efficiency of metal anion sorption due to their competitor effect for interaction with protonated amine groups. While the presence of chloride at low concentration allowed the formation of chloro-anionic species for platinum and palladium, thus improving sorption capacities, at high concentration it greatly reduced metal recovery on glutaraldehyde cross-linked chitosan [44]. This competitor effect may be reduced by chemical modification of the chitosan (grafting of chelation groups, such as sulfur compounds) $[132,135]$. The selective sorption of metals can also be increased by modification of the chemical structure of the polymer using, for example, a template formation procedure $[64,68,203]$.

Rhazi et al. [204] point out that the affinity of chitosan for cations does not depend on the physical form of the polymer (either as a film, powder or in solution) and that the selectivity does not depend on the size and hardness of considered ions.

\subsection{Metal desorption and sorbent recycling}

The use of chitosan for metal recovery can be limited by the cost of the polymer compared to other waste materials. Except in the case of precious metals for which the cost of the sorbent is not a limiting criterion (taking into account the high sorption capacities that can be achieved), the recycling of the polymer is a required step in the design of the process. The recovery of the metal is also an important parameter for the economics of the process [205].

This aspect has not been adequately studied and there is very little literature focusing on this topic. However, the sorption mechanisms involved in metal uptake can provide an orientation for the design of the desorption strategy. In the case of the sorption of metal cations, the chelation mechanism is very sensitive to $\mathrm{pH}$ and usually sorption does not occur at low $\mathrm{pH}$. Therefore, a simple change in the $\mathrm{pH}$ of the solution may reverse the reaction. However, to prevent the polymer dissolving it will be necessary to use sulfuric acid [48]. It would be also possible to use a strong chelating agent (such as EDTA): the complexation of the metal by the ligand can displace the metal from the sorbent [206]. However, this method is more complex and the eluate contains chelated metal, which is less easy to recycle. The method of $\mathrm{pH}$ change has also been successfully used for desorbing metal anions from loaded sorbent. However, in this case it was necessary to increase the $\mathrm{pH}$ using sodium hydroxide (or ammonium hydroxide) [167,207]. Molybdate and vanadate were completely recovered from loaded phases using sodium hydroxide solutions at $1 \mathrm{M}$ concentration. The sorbent can be successfully re-used for at least 10 cycles with no significant decrease in sorption capacities [207], but its recycling requires re-conditioning of the polymer in acidic conditions prior to subsequent cycles of metal sorption.

However, desorption of metal anions cannot be systematically achieved in alkaline conditions. For example, in the case of precious metal sorption, the strength of sorbent-metal interactions does not allow a significant fraction of the metal to be recovered and better desorption is achieved using very acidic solutions ( $\mathrm{HCl}$ for example at concentration higher than $3 \mathrm{M}$ ) or strong chelating agents such as thiourea at $0.5 \mathrm{M}$ concentration (Chassary, unpublished results). However, these treatments are generally very drastic and do not allow the recycling of the sorbent.

\section{Controlling parameters}

There are a number of experimental parameters controlling sorption properties (sorption capacities, 
uptake kinetics): $\mathrm{pH}$, metal concentration, matrix of the solution, size of sorbent particles, structure and conditioning of the polymer. However, most of these parameters control sorption performance through 3 criteria/mechanisms: (a) the crystallinity of the sorbent, (b) its diffusion properties and (c) the speciation of the metal (in relation with the protonation of the amine groups of the polymer and the composition of the solution).

\subsection{Crystallinity and swelling properties}

Though hydroxyl groups on chitosan may be involved in bonds with metal ions, the main active groups remain the amine functions. Therefore, one of the controlling parameters should be the deacetylation degree of the polymer. However, several studies have shown that it is not really the total number of free amine groups that must be taken into account but the number of available free amine groups $[46,47,159]$. The availability of amine groups may be controlled by two parameters: (a) the crystallinity of the polymer and (b) the diffusion properties (discussed later).

Piron and Domard [46,47,159] conditioned the chitosan in a different way by dissolving and direct freeze-drying of the solution, and investigated the sorption properties of these samples for uranium sorption. They observed that the sorption capacity can be directly correlated to the crystallinity index. Swelling in water, together with the size of chitosan particles and the crystallinity, governs the kinetics of metal diffusion and sorption. They conclude that the key parameter is the molecular mobility of the chains. This parameter influences both the sorption capacity at equilibrium (controlling the number of available and accessible sorption sites) and the uptake kinetics (swelling kinetics and diffusion properties). They point out the influence of pre-hydration on kinetic control (through the influence of crystallinity). Since the crystalline regions of the polymer are not accessible to water and metal ions (except at the surface of the particle), the effect of crystallinity is especially important when large particles are used.

Kurita's group investigated the influence of chitosan modification (glutaraldehyde cross-linking and acylation) on the sorption of copper and mercury. The impact of chitosan modification depends on the mode of chemical modification (homogeneous versus heterogeneous modification). The substitution of new groups on the polymer improves the sorption capacity up to a maximum that depends on the metal, and the chemical derivative, before a decrease in sorption capacity occurs as the degree of substitution increases $[92,93,208-210]$. The increase in sorption efficiency at low substitution degree may be attributed to the low levels of cross-linking, which prevent the formation of closely packed chain arrangements without a significant decrease in the swelling capacity. At higher levels of cross-linking the precipitated material has lower swelling ability. The accessibility decreases due to a more extensive three-dimensional network and to an increase in the hydrophobic character.

In the case of metal anion sorption, the influence of this parameter is complex. Molybdate sorption was investigated using chitosan flakes (of different sizes) of different characteristics (molecular weight, degree of deacetylation, and crystallinity) in their raw form and after chemical cross-linking with glutaraldehyde [42]. The best sorbents were characterized by the absence of a peak at $2 \theta=22^{\circ}$ in X-ray diffraction patterns, while the worst samples were characterized by a peak at this angle, which is typical of the allomorphic crystalline form of chitosan (the so-called "tendon" form, [40]). These results confirm that the crystallinity strongly influences sorption properties. The heterogeneous cross-linking of chitosan flakes resulted in a significant decrease in sorption capacities for large particle sizes, whatever the characteristics of the chitosan samples, while for small particle sizes the sorption capacities were comparable for raw and cross-linked materials. The cross-linking of large particles reduces the accessibility of internal sorption sites to water and metal ions, especially in the case of molybdate anions, which are adsorbed by the electrostatic attraction of polynuclear anionic molybdate species on protonated amine groups [166,211]. The diffusion of these poly oxo-anions may be restricted by (a) steric hindrance due to their large size and the restriction of the opening of the polymer network and by (b) a modification of swelling properties. Therefore, the sorption may be limited to the external layers of the polymer. It is interesting to observe that when the polymer is conditioned in the form of gel beads, the cross-linking treatment does not influence the sorption performance (at equilibrium and kinetic rates). In this case, the manufacturing of the beads 
includes the dissolving of the polymer that loses its crystallinity, and the coagulation process without the drying step does not restore the crystallinity of the material, as would occur with dried material.

Similar studies were performed on the influence of chitosan origin and characteristics on platinum sorption [212,213]. Squid chitosan was less efficient for platinum sorption compared to fungal and shrimp chitosan, which was explained by its higher crystallinity. The effect of the degree of acetylation was highly dependent of the origin of chitosan: sorption capacity increased with decreasing degree of acetylation in the case of shrimp chitosan while it decreased for squid chitosan. The decrease of the degree of acetylation hardly affected sorption kinetics, while it strongly controlled sorption kinetics for squid material. These differences may be explained by the difference in crystallographic properties. The samples were submitted to different treatments such as dissolving and drying, dissolving and freeze-drying, dissolving, precipitation and drying (or freeze-drying). These treatments did not significantly change the crystallographic properties of the sorbents, nor their sorption properties, except in the case of the samples that were re-precipitated before the drying step. In this case, the re-precipitation and the drying step (especially in the oven-drying procedure) significantly influenced the crystallographic properties, which in turn influenced sorption properties: the freeze-drying procedure enhanced sorption properties when applied to the dissolved and re-precipitated material $[212,213]$.

\subsection{Diffusion properties}

Many studies have pointed out the slow kinetics for metal sorption on chitosan compared to other sorbents. Chitosan has a very low specific surface area ranging between 2 and $30 \mathrm{~m}^{2} \mathrm{~g}^{-1}$ [33,192]. Glutaraldehyde cross-linked chitosan gel beads have a higher specific surface area around $180-250 \mathrm{~m}^{2} \mathrm{~g}^{-1}$ [207]. Porosity measurements have shown that chitosan has a single-phase homogeneous gel matrix (microporous) rather than a two-phase heterogeneous (macroporous) one, and hence an average pore size ranging between 300 and $550 \AA$ [192]. In the case of glutaraldehyde cross-linked chitosan gel beads, the diameter of pores was measured by different techniques (BET measurements, size exclusion chromatography) and was found to be between $560 \AA$ [43] and 700-900 $\AA$ [207]. These average values are of the same order of magnitude as those given by Kawamura et al. [84] for PEI-grafted chitosan gels beads (mean diameter close to $1000 \AA$ ). Gel bead conditioning significantly modifies the porous characteristics of the polymer, which may explain the differences in the sorption properties of these materials $[44,45,51,76,214]$.

Changing the size of the particle influences equilibrium performance, especially in the case of chitosan flakes after chemical cross-linking [42], and sorption kinetics: the time required to reach the equilibrium significantly increases with the size of sorbent particles $[109,165,192,194,214]$. Restrictions to diffusion may explain this behavior and intraparticle diffusion is frequently considered to be the limiting step in the sorption process. Modifying the structure of the polymer by gel bead manufacturing is an efficient process for improving diffusion properties. The main drawback of preparing gel beads for metal ion sorption is the high water content (high porous volume of the beads); as a result, the volumetric density of sorption sites is significantly lower than that of the original material, which in turn drastically reduces the volumetric sorption capacity of the sorbent. Moreover, it means designing large-scale sorption units and handling huge amounts of wet sorbents. Several procedures have been used to compensate this drawback including grafting supplementary sorption sites (PEI-grafting) to increase the density of sorption sites [52,83,84,86,95,136,215]. It is also interesting to dry the sorbent to reduce water content. However, the drying usually leads to the collapse of the structure of the polymer, which therefore loses its enhanced porous properties. Freeze-drying would be a possible solution for avoiding this decrease of diffusion properties; however, the process is expensive for the preparation of large amounts of material. A controlled-drying procedure has been developed using a two-step process. Gel beads are mixed with a saturated solution of saccharose before being dried. The presence of saccharose inside the polymer network during the drying step prevents the structure from collapsing. Before being used, the beads have to be rinsed with water to remove saccharose. The beads swell slightly and though they do not recover their initial diameter they maintain a highly porous structure. With this controlled drying procedure the sorption kinetics are comparable to those of the raw material, 
unlike beads dried under uncontrolled-conditions [63].

An alternative to gel bead conditioning is depositing the polymer as a thin layer on a suitable support: chitosan was immobilized on alumina membranes (through different procedures involving drying, precipitation ... ) for copper sorption [216], non porous gel beads were also tested as a support for chitosan using a chemical linker [217]. In this case, the procedure is relatively expensive and should be limited to the preparation of specific supports for analytical purposes (pre-concentration step) rather than for large-scale metal recovery processes.

\subsection{Metal speciation}

The influence of metal speciation has received limited attention from researchers. Recently, a few papers have focused on the influence of metal speciation on sorption properties and uptake mechanism $[52,83,85,86,166,167]$.

\subsubsection{Case of Pd(II) and Pt(IV)}

In the case of palladium sorption on glutaraldehyde cross-linked chitosan, the influence of metal speciation has been pointed out [94]. The optimum $\mathrm{pH}$ for palladium sorption is close to $\mathrm{pH} 2$. However, the efficiency of the sorbent (marked by the shape of sorption isotherm) strongly depends on the acid used for $\mathrm{pH}$ control of the solution. With hydrochloric acid solutions, the Langmuir-type sorption isotherm (very favorable, almost irreversible) was obtained with a sharp initial slope. In the case of sulfuric acid solutions, the maximum sorption capacity was comparable to that obtained with $\mathrm{HCl}$ solutions, but the initial slope of the sorption isotherm was comparatively much lower, indicating a lower affinity of the sorbent for the metal. In this solution, chloride ions are only brought about by the dissociation of palladium salt (palladium chloride) and there is a lack of chloride ions for the formation of chloro-anionic species. Therefore, the distribution of palladium species is not favorable to metal sorption and the sorption increases when metal concentration increases (correlatively to chloride ions). In the case of platinum, sorption in sulfuric acid solutions was also significantly lower than that obtained in $\mathrm{HCl}$ solutions (under comparable experimental conditions) but when chloride ions were added to the solution, the sorption capacity increased due to the formation of more adsorbable species [132]. The addition of chloride ions may not exceed $0.1 \mathrm{M}$, above this limit value the excess of chloride induces a strong competition effect which again limits sorption efficiency. The influence of metal speciation can be inhibited when using chitosan derivatives. In the case of platinum sorption using chitosan-based materials, the grafting of thiourea on chitosan partially changed the sorption mechanism: new chelating functionalities were added to the ion exchange resin and it became less sensitive to the presence of competitor ions and also more reactive to $\mathrm{Pd}^{2+}$ species [132].

Similar observations about the influence of the acid used for $\mathrm{pH}$ control have been made for the sorption of a heavy (non-noble) metal, ca. mercury, on polyaminated highly porous chitosan chelating resins [83]. It was observed that mercury was adsorbed on the sorbents under experimental conditions that correspond to the predominance of non-dissociated species (ca. $\mathrm{HgCl}_{2}$ ), and it was concluded that mercury uptake occurred through a chelation mechanism on nitrogen groups. However, it was observed that with a large excess of chloride in the solution, the sorption capacity decreased due to the ionization of $\mathrm{HgCl}_{2}$ to form $\mathrm{HgCl}_{4}{ }^{2-}$. Comparing the sorption capacities for solutions prepared in the presence of sodium chloride and hydrochloric acid, it was observed that for a similar chloride concentration, the saturation capacity was greater in $\mathrm{HCl}$ solutions than in $\mathrm{NaCl}$ solutions. The change in the effect of solution composition can be explained by a change in the sorption mechanism.

Chelation mechanism:

$\mathrm{R}_{1} \mathrm{R}_{2} \mathrm{R}_{3} \mathrm{~N}+\mathrm{HgCl}_{2} \Leftrightarrow \mathrm{R}_{1} \mathrm{R}_{2} \mathrm{R}_{3} \mathrm{~N}-\mathrm{HgCl}_{2}$

Ion exchange mechanism:

$\mathrm{R}_{1} \mathrm{R}_{2} \mathrm{R}_{3} \mathrm{~N}+\mathrm{HCl} \Leftrightarrow \mathrm{R}_{1} \mathrm{R}_{2} \mathrm{R}_{3} \mathrm{NH}^{+} \mathrm{Cl}^{-}$

$$
\begin{aligned}
& \mathrm{R}_{1} \mathrm{R}_{2} \mathrm{R}_{3} \mathrm{NH}^{+} \mathrm{Cl}^{-}+\mathrm{HgCl}_{3}{ }^{-} \\
& \quad \Leftrightarrow \mathrm{R}_{1} \mathrm{R}_{2} \mathrm{R}_{3} \mathrm{NH}^{+} \mathrm{HgCl}_{3}{ }^{-}+\mathrm{Cl}^{-}
\end{aligned}
$$

It was also observed that mercury was not adsorbed from solutions whose $\mathrm{pH}$ was controlled with sulfuric acid. This decrease in sorption capacity can be explained by the protonation of amine groups and the formation of ion pairs with sulfate ions near protonated amine groups (in Eq. (10), sulfate ions are substituted 
to chloride ions). Since mercury does not form complexes (and more specifically anionic complexes) with sulfate, $\mathrm{HgCl}_{2}$ is not ionized and mercury species cannot be exchanged, as seen in Eq. (11). Mercury speciation is thus revealed to be a key parameter: more specifically the complexation of mercury strongly influences sorption efficiency.

\subsubsection{Case of $M o(V I)$ and $V(V)$}

In the case of molybdate and vanadate sorption, the distribution of metal species was determined at different $\mathrm{pHs}$ with varying total metal concentration and it was shown that many different metal species may coexist in the solution $[166,167]$. Their fractions depend on these two parameters and they strongly change the charge and the size of metals ions that predominate in the solution. A comparison of the profiles of sorption isotherms at different $\mathrm{pHs}$ with the distribution of poly-nuclear poly-anionic species confirmed that the sorbent has a marked preference for these species: heptamolybdate species and decavanadate species, for Mo and $\mathrm{V}$, respectively. It was possible to plot the sorption capacity in function of the concentration of heptamolybdate species and the resulting plot was typical of Langmuir-type isotherms [166,167]. On the other hand, when the sorption capacity was plotted versus total metal concentration the sorption isotherm was characterized by an initial stage for which sorption remained negligible up to a residual concentration that corresponded to the beginning of the formation of adsorbable poly-nuclear species: this limit concentration obviously varies with the $\mathrm{pH}$ of the solution.

\subsubsection{Case of metal chelation (Cu(II), $\mathrm{Ag}(\mathrm{I}))$}

The effect of speciation on the change of metal uptake mechanism has been evocated in the case of palladium and platinum (Section 5.3.1) with a comparison to the case of mercury uptake in the presence of chloride ligands. Another interesting example of the effect of metal speciation on the uptake mechanism is given by the case of copper recovery from solutions containing ligands. The optimum $\mathrm{pH}$ for copper sorption is around $\mathrm{pH}$ 5. Due to precipitation phenomena, depending on the total concentration of copper, it is impossible to investigate sorption at higher pHs. However, when chelating agents (such as tartarate, citrate or EDTA) are present in the solution, the limit $\mathrm{pH}$ for precipitation is increased: this change in the
$\mathrm{pH}$ for precipitation can be a problem for wastewater treatment since conventional precipitation processes cannot be applied. Juang and Ju [85] have shown that in the presence of chelating agents copper can be sorbed on chitosan but at lower $\mathrm{pH}$. The protonation of amine functions on the sorbent and on the PEI grafted on the polymer makes the material efficient at sorbing anionic copper species by electrostatic attraction. Indeed, in equimolar diluted solutions containing cupric ions and EDTA, over a wide range of $\mathrm{pHs}$ (between $\mathrm{pH} 3$ and $\mathrm{pH} 12$ ), the predominant species is $\mathrm{Cu}(\mathrm{EDTA})^{2-}$, while at lower pHs, copper is present in solution in the form of $\mathrm{CuH}$ (EDTA). They observed that the sorption capacity was very low below $\mathrm{pH} 3$ due to the weaker electrostatic attraction of mono-charged species by the ammonium groups of PEI immobilized on the sorbent. This decrease in the sorption properties may also be due to the strong chelation of hydroxo complexes of $\mathrm{Cu}$ (EDTA) chelates, which makes this water-soluble compound less reactive for amine and ammonium groups on the sorbent in the very acidic region. Finally, they observed that when the $\mathrm{pH}$ was increased, the sorption capacity increased again. They suggested that this might be caused by competitive reactions of protonation and complex binding. Under selected experimental conditions corresponding to the formation of anionic chelated copper species, the interaction between chitosan and the metal is an electrostatic attraction. When the experimental conditions change (change in the protonation, change in the speciation of copper to form less anionic species), the sorption mechanism may be partially replaced by a chelation mechanism. Wu et al. [218] investigated the influence of the $\mathrm{pH}$ on copper(II) sorption on chitosan in the presence of chelating agents. The sorption isotherms are strongly influenced by the nature of the chelating agent, the $\mathrm{pH}$, and the concentration of the metal (equimolarity of metal and ligand). They observed an increase in the $\mathrm{pH}$ of the solution after metal sorption. Under non-controlled acidic $\mathrm{pH}$ conditions, they observed that sorption isotherms are very favorable at low metal concentration in the absence of chelating agent and in the presence of gluconate, tartarate, and citrate. Under similar conditions, in the presence of EDTA, the affinity of chitosan for copper was considerably reduced. In acidic solutions, copper was present in the form of $\mathrm{CuH}(\mathrm{EDTA})^{-}$ and to a lesser extent $\mathrm{Cu}(\mathrm{EDTA})^{2-}$ [219]; however, 
$\mathrm{H}_{2}$ (EDTA $^{2-}$ anions were also present and they competed with copper chelates for sorption on protonated amine groups. This competition effect did not occur with the other ligands (not ionized under selected $\mathrm{pH}$ conditions). By increasing the residual concentration (above $0.4-0.5 \mathrm{mM}$ ), the sorption capacity decreased again in the presence of EDTA, tartarate and citrate, while with gluconate as the chelating agent, sorption capacities continue to increase up to a residual concentration corresponding to a plateau at a value slightly lower than the maximum sorption capacity obtained in the absence of a chelating agent. The weak effect of gluconate may be explained by the low formation constant of this ligand compared to those of the other ligands. Depending on the $\mathrm{pH}$ of the solution, the mechanism may change: electrostatic attraction of anionic chelates, and/or coordination of $\mathrm{Cu}(\mathrm{II})$ with unprotonated amine groups. Changing the $\mathrm{pH}$ changes the protonation of the polymer but also the distribution of metal species. Consequently, the optimum $\mathrm{pH}$ for copper sorption in the presence of ligands depends on the chelating agent: $\mathrm{pH} 3.1-4.2$, 5.0-5.8, 5.0-6.0, and 5.2-5.8 for EDTA, citrate, tartarate and gluconate, respectively. They observe that the optimum $\mathrm{pH}$ presents a slightly acidic front compared to the equivalent points on titration curves: the aqueous-phase complexation of $\mathrm{Cu}(\mathrm{II})$ and chelating agents starts to occur after optimum $\mathrm{pH}$, and coordination of $\mathrm{Cu}$ (II) with unprotonated amine groups dominates in less acidic solutions.

Baba et al. [66] prepared a chitosan derivative ( $N$-(2-pyridylmethyl)chitosan) in order to improve the sorption selectivity of copper(II) over iron(III). They compared the sorption properties of copper in different media (including sodium nitrate and ammonium nitrate) at several $\mathrm{pH}$. They observed that in the presence of sodium nitrate, the distribution coefficient ( $D=$ (metal concentration in the solid)/(metal concentration in the aqueous phase), $1 \mathrm{~kg}^{-1}$ ) for copper sorption increased continuously with $\mathrm{pH}$ up to $\mathrm{pH}$ 5-6 (below the precipitation domain). In the presence of ammonium nitrate, the distribution coefficient increased up to $\mathrm{pH} 3-4$ (with values comparable to those obtained with sodium nitrate solutions), but remained constant up to $\mathrm{pH}$ 6-6.5, and then decreased again. In the presence of ammonia, at near neutral or alkaline $\mathrm{pH}$, copper ions were complexed as $\mathrm{Cu}\left(\mathrm{NH}_{3}\right)_{\mathrm{i}}{ }^{2+}$ $(i=1-4)$ and did not precipitate. These complexes cannot be adsorbed on the chitosan derivatives. In the low $\mathrm{pH}$ region, copper complexes (with ammonia and hydroxide) are not formed and copper can be directly adsorbed in the form of copper nitrate, as indicated in the following equations:

Polymer protonation in the low $\mathrm{pH}$ region:

$\mathrm{RNN}_{(\mathrm{s})}+2 \mathrm{H}^{+}+2 \mathrm{NO}_{3}{ }^{-} \Leftrightarrow \mathrm{RNN}\left(\mathrm{HNO}_{3}\right)_{2(\mathrm{~s})}$

Chelation:

$$
\begin{gathered}
\mathrm{RNN}_{(\mathrm{s})}+\mathrm{Cu}\left(\mathrm{NH}_{3}\right)_{i}{ }^{2+}+2 \mathrm{NO}_{3}{ }^{-} \\
\Leftrightarrow \mathrm{RNNCu}\left(\mathrm{NO}_{3}\right)_{2(\mathrm{~s})}+i \mathrm{NH}_{3}
\end{gathered}
$$

In the $\mathrm{pH}$ range for which copper is strongly complexed by ammonia, the addition of ammonium chloride considerably reduces the sorption efficiency, since the metal is less available for sorption on amine groups. On the other hand, by decreasing the $\mathrm{pH}$, the formation of ammonia-copper complexes is reversed, and ammonia does not change sorption performance.

Lasko and Hurst [169] studied silver sorption on chitosan under different experimental conditions, changing the $\mathrm{pH}(2,4,6,8$ and 10$)$ in the presence of several ligands. They compared the sorption performances of chitosan to those of 4 commercial resins: Amberlite IRA-67 (weakly basic, polyamine functional groups), IRA-458 (strongly basic, quaternary ammonium functional groups), IRC-718 (iminodiacetic acid functional groups) and Duolite GT-73 (thiol functional groups). In the presence of chelating agents, silver ions $\left(\mathrm{Ag}^{+}\right)$appeared in the solution under cationic forms, $\mathrm{Ag}\left(\mathrm{NH}_{3}\right)_{2}{ }^{+}$, with ammonia, and anionic forms, $\mathrm{Ag}(\mathrm{CN})_{2}{ }^{-}, \mathrm{Ag}(\mathrm{SCN})_{3}{ }^{2-}$, $\mathrm{Ag}\left(\mathrm{S}_{2} \mathrm{O}_{3}\right)_{2}{ }^{3-}$ with cyanide, thiocyanate and thiosulfate, respectively. As expected, cationic forms were adsorbed at near-neutral $\mathrm{pH}$ (4-8), when the chitosan amine groups were unprotonated and the electron pair on the amine nitrogen was available for donation to silver. On the other hand, at low $\mathrm{pH}$, the protonation of amine groups allowed metal anions to be sorbed: $\mathrm{Ag}(\mathrm{SCN})_{3}{ }^{2-}$ and $\mathrm{Ag}\left(\mathrm{S}_{2} \mathrm{O}_{3}\right)_{2}{ }^{3-}$ were efficiently sorbed at $\mathrm{pH} 2$, while at $\mathrm{pH} 4$, sorption was drastically reduced and null at neutral or alkaline $\mathrm{pH}$. Silver cyanide ions were not sorbed on chitosan whatever the $\mathrm{pH}$ : because of precipitation of silver cyanide at $\mathrm{pH} 2$, it was impossible to study behavior at this $\mathrm{pH}$, whereas this $\mathrm{pH}$ should be the optimum $\mathrm{pH}$ for the sorption of this anionic form. In the case of $\mathrm{Ag}^{+}$ 
sorption, sorption performances (at each $\mathrm{pH}$ ) were comparable for chitosan and Amberlite IRC-718, Duolite GT-73 was better at $\mathrm{pH}$ 2: the chelating resins exhibited a behavior similar to that of chitosan. On the other hand, the anion exchange resins (Amberlite IRA-67 and IRA-458) were not efficient at removing silver, independently of the $\mathrm{pH}$. For silver sorption in the presence of chelating thiosulfate, the chelating resins (Duolite GT-73 and Amberlite IRC-718) only adsorbed silver in alkaline solutions, while Amberlite IRA-67 removed silver thiocyanate with comparable efficiency between $\mathrm{pH} 2$ and $\mathrm{pH}$ 6. Amberlite IRA-458 strongly adsorbed silver thiocyanate independently of the $\mathrm{pH}$. Chitosan was able to sorb silver species through different mechanisms (ion exchange and chelation), but compared to reference commercial resins (bearing similar functionalities) this biopolymer was more sensitive to the $\mathrm{pH}$.

\section{Modes of application}

The biopolymer can be conditioned and used for metal ion sorption in different forms; however, depending on the physical state of the material, the application process significantly changes.

\subsection{Water-soluble polymers and ultrafiltration}

Chitosan is soluble in most acids; however, its solubility depends on several parameters such as the deacetylation degree of the polymer, the polymer weight, acid and polymer concentrations, and ionic strength. Depending on the $\mathrm{pH}$ the extent of polymer protonation significantly changes and according to the conclusions of the section on sorption mechanisms the polymer is capable of either metal cation chelation (near neutral $\mathrm{pH}$ ) or metal anion electrostatic attraction (in acidic solutions). Basically, the polymer reacts with metal ions on the same basis as with solid-form of chitosan (this has been described in Section 3). The change in the $\mathrm{pH}$, in the composition of the solution (presence of ligands, metal complexation) leads to a change in the binding mechanism (electrostatic attraction versus chelation, or reciprocal). In most cases, the binding of metal ions onto chitosan dissolved in the solution leads to their immobilization on the macromolecule. Using dialysis membrane allows for example retaining the loaded macromolecule while unbound metal ions pass through the membrane. This can be used to determine the selectivity of chitosan for the complexation of metal ions in multi-component solutions [220]. The stronger the binding of the metal the lower the amount of metal passing through the membrane.

The interaction of the polymer with metal ions may also cause, in selected experimental condition, the gelation of the polymer and the coagulation/flocculation of the metal $[173,174]$. In the case of metal anions for example these interactions contribute to the neutralization of cationic charges of chitosan dissolved in acidic solutions and then the polymer may re-precipitate or form aggregates that result in the formation of flocs.

However, in most cases, the interactions of metal ions with chitosan do not lead to the formation of flocs able to settle and metal ions remained bound to the polymer but soluble in the solution. Therefore, it is necessary to recover the polymer by a suitable filtration process. Certain solution components will pass through the membrane, forming the permeate, whereas others will be retained by the membrane, forming the retentate or concentrate. Retention of the components by the membrane depends on many parameters including solution type, solution composition, $\mathrm{pH}$, temperature, membrane material, pore size, hydrodynamics, etc. In many cases, however, the size of the dissolved component is the crucial factor for retention and increasing the size of the component by chelation or more generally interaction with a soluble macromolecule forms the basis of the so-called polymer-enhanced ultrafiltration (PEUF) process [221]. This process has been used with several soluble macromolecules; most of them being synthetic polymers (poly(ethylenimine), poly-acrylate ... polymers) [222], but natural polymers have been successfully used for the recovery of metal ions from dilute solutions [223-225]. In the case of mercury removal using chitosan, a comparison of recovery efficiency (measured on the basis of metal/amine group molar ratio) for metal sorption on chitosan flakes and metal recovery by PEUF showed that the polymer is best used in dissolved form [226]. The change in polymer conformation, which results from dissolving, enhances the accessibility to amine groups and therefore increases sorption capacities and uptake kinetics. 
Rhazi et al. compared the molar ratio $-\mathrm{RNH}_{2} / \mathrm{Me}$ for sorption (on solid particles) and complexation (dissolved chitosan) for different metals and found that it increases substantially when chitosan is used in a dissolved state. It is possible to concentrate the metal in the retentate for electrolytic recovery or for a de-complexation procedure (changing for example the $\mathrm{pH}$ of the solution) for the recycling of the polymer.

Retention performance will depend on (a) the characteristics of the solution the presence of salts, the ionic strength causing coiling of the polymer change the retention of the polymer; (b) the characteristics of the polymer, its deacetylation degree for example but more significantly its molecular weight (since it controls polymer retention).

At lab-scale, discontinuous systems may be used (such as Amicon cells) for the optimization of uptake process, while at large scale continuous systems using plane membrane systems (organic membranes) or tubular modules (mineral membranes) are preferred.

\subsection{Flakes and gel beads}

Most of the studies dedicated to metal ion sorption have investigated the use of the polymer in the form of flakes or powders, using batch systems with stirring. Some studies have been performed in dynamic systems using fixed-bed columns [206,227-229]. However, due to the resistance to intraparticle diffusion, and the sorption limitations it may induce, it is necessary to reduce the size of sorbent particles as much as possible. The characteristics of these particles (density, shape and size) usually introduce strong hydrodynamic limitations such as head loss and column clogging, which limit the possibility to use these systems for large-scale columns [230]. For these reasons it seems that a continuously stirred tank reactor would be more appropriate for using chitosan flakes [202]. The alternative consists in using chitosan gel beads; in this case, the expansion of the polymer network and the decrease in its residual crystallinity improve mass transfer properties, and the shape of sorbent particles enhances the hydrodynamic properties. Fixed-bed columns are frequently used for the recovery of metal ions with chitosan gel beads, investigating the influence of parameters such as superficial flow velocity, particle size, metal concentration, column depth $[45,53,84]$. Different models have been used to describe breakthrough curves for designing and scaling up the process: empirical models such as the Bohart-Adams model [228] and the Clark model $[227,228]$ or mass transfer models [84,228]. The advantage of using fixed-bed columns is the easy recycling of the polymer after use and after desorption, which can be carried out in the same column. In the case of the sorption of metals that are difficult to desorb or those cases for which desorption significantly diminishes sorption efficiency, the fixed-bed system does not appear to be the best mode of application.

\subsection{Membranes}

Muzzarelli [231] reported a decrease in the metal ion sorption efficiency of chitosan membranes compared to chitosan flakes and attributed this effect to a decrease in contact surface, despite the thickness of the membrane $(\sim 20 \mu \mathrm{m})$. However, he observed a crystallization of the polymer during the manufacturing of the membrane and this may be another interpretation of the decreasing sorption efficiency. The drying of the membrane during preparation causes the irreversible collapse of the structure (as we mentioned for the drying of chitosan gel beads) and a re-organization of the polymer, inducing partial re-crystallization. Direct extrusion of the membrane in the coagulation bath could be a solution to maintain the diffusion properties of these membranes. In this case, it would be possible to use this kind of chitosan membrane as circulating bands passing through the solution to be treated. In a second step, the membrane should be immersed in a desorption bath to remove the metal from the polymer membrane (prior to recirculation in the sorption tank), as was suggested by SenGupta for synthetic polymer membranes [232].

Krajewska prepared chitosan gel membranes and extensively characterized their diffusion properties [233-235]. The permeability of metal ions through these membranes was measured and the permeability scale was as follows: $\mathrm{Cu}<\mathrm{Ni}<\mathrm{Zn}<\mathrm{Mn}<\mathrm{Pb}<$ $\mathrm{Co}<\mathrm{Cd}<\mathrm{Ag}$ [236]. Krajewska correlated this scale to that of chitosan-metal affinity and concluded that the diffusive properties of chitosan membranes towards metal ions offer potential for protection of chitosan-based biological systems against the destructive effects of heavy metals. This should be also extended to applications in the packaging industry. 


\subsection{Fibers and hollow fibers}

Chitosan fibers have been studied for the recovery of dyes and amino acids [237,238], but less attention has been paid to the use of this conditioning of the polymer for the recovery of metal ions. This physical state of the chitosan would be compatible for use in column systems, allowing easier hydrodynamic transfer through the column at the expense of a necessary recycling of the solutions to increase contact time and limit the effect of short-cuts.

Hollow fibers have recently received attention with the objective of performing the simultaneous sorption and desorption of the target metal $[61,62]$. Hollow chitosan fibers were prepared and the system was used for the recovery of chromate anions at $\mathrm{pH} 3$. The hollow fibers were immerged in the chromate solution while an extractant (Aliquat 336 dissolved in a hydrocarbon solvent: kerosene) was flowed through the lumen of the fiber. Chromate anions adsorbed on the fiber were re-extracted by the solvent extractant. The hollow fiber acts simultaneously as a physical barrier for the solvent extractant and as a reactive barrier that can make the extraction process more selective. For example in

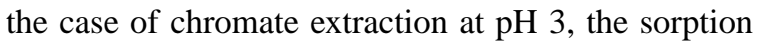
process was an electrostatic attraction mechanism: as a consequence, metal cations are not expected to be efficiently adsorbed under the selected experimental conditions.

\subsection{Miscellaneous}

Chitosan has been also used recently in solvent extraction processes, through different strategies. Inoue et al. $[239,240]$ synthesized a modified lipophilic chitosan (obtained by dithiocarbamate grafting onto di-dodecanoylchitosan) for use in aliphatic diluents such as kerosene and tested this process for the extraction of various metals including copper, nickel, iron, cobalt and zinc. These soluble derivatives can be used in batch, column pulsed-column systems as in traditional solvent extraction processes [241]. Recently, it was also reported that chitosan can be used as a support for liquid extractant in order to prepare solvent impregnated resins [242]. The resulting impregnated sorbent was successfully used for $\mathrm{Cr}$ (III) recovery. It is possible to introduce a liquid extractant into the solvent system in order to improve extraction efficiency and selectivity. Cyanex 302 was used for the impregnation of the chitosan gel beads and for the extraction of cadmium [243]. The impregnation of the chitosan support with Cyanex 302 maintained good chitosan extraction efficiency for cadmium over a wide range of $\mathrm{pH}$ compared to raw chitosan beads. Future development might focus on the use of lipophilic derivatives of chitosan to improve the stability of the solvent system on the support.

\section{Summary of metal ion sorption capacities of chitosan-based materials}

The following tables (Table 4 for metal cations and Table 5 for metal anions) briefly report the maximum sorption capacities that were cited for uptake of different metals, with the corresponding references. A direct comparison of experimental data is not possible since experimental conditions $\mathrm{pH}, \mathrm{pH}$ control, sorbent particle size, conditioning, and composition of the solution) are not systematically the same. Moreover, despite the number of papers published on this topic, there is little literature containing a full study of sorption isotherms with an extensive description of experimental conditions. However, these tables provide basic information to evaluate the possibility of using chitosan for metal ion uptake. Additional references are cited in the Tables on research dealing with the sorption of given metals by chitosan derivatives. Obviously, this list of references is not exhaustive but reminds some basic works.

\section{Considerations on the competitiveness of chitosan materials for metal ion recovery against conventional processes-limiting parameters for large-scale applications}

Several studies have attempted to compare the cost of sorption process on chitosan to conventional processes. Coughlin et al. [205] conclude that sorption on chitosan is competitive against precipitation technique for copper recovery from electroplating wastewater. Wan Ngah and Isa [244] compare chitosan sorbent to synthetic resins and found that sorption capacities were significantly greater for the biopolymer in the recovery of copper than Dowex A-1 and Zerolit 225 
Table 4

Summary table for the sorption capacities $\left(q_{\max }, \mathrm{mmol} \mathrm{Me}^{-1}\right)$ of some metal cations on chitosan-based materials

\begin{tabular}{|c|c|c|c|c|c|c|}
\hline Metal & Sorbent & Form & $\mathrm{pH}$ & $q_{\max }$ & Reference & Add. Ref. \\
\hline \multirow[t]{11}{*}{$\mathrm{Cu}(\mathrm{II})$} & $\mathrm{R}, \mathrm{C}$ & Beads & 6 & $0.7-1.3$ & {$[53]$} & {$[53]$} \\
\hline & $\mathrm{C}$ & Beads & 5 & 3.2 & [91] & \\
\hline & $\mathrm{R}$ & Flakes & 4.2 & 0.6 & [193] & {$[9,17,32,143,151,153,190,204,206]$} \\
\hline & $\mathrm{R}$ & Flakes & $5-6$ & 1.5 & [205] & \\
\hline & $\mathrm{R}, \mathrm{C}$ & Membr. & $5-6$ & 3.2 & [216] & \\
\hline & $\mathrm{R}, \mathrm{C}$ & Depos. & $5-6$ & $1.4-2.3$ & [87] & {$[99,115,123,138,154,210]$} \\
\hline & $\mathrm{R}, \mathrm{M}$ & Flakes & 5.6 & $0.9-2.2$ & [131] & \\
\hline & $\mathrm{C}, \mathrm{M}$ & Flakes & $5-6$ & 2.5 & {$[68]$} & \\
\hline & $\mathrm{R}$ & Flakes & 5.7 & 1.2 & [204] & \\
\hline & $\mathrm{R}$ & Flakes & $3.5 / 4.5$ & 1.2 & [181] & \\
\hline & $\mathrm{R}$ & Flakes & 5 & $1.5-2.5$ & [189] & \\
\hline \multirow[t]{5}{*}{$\mathrm{Cd}(\mathrm{II})$} & $\mathrm{R}$ & Flakes & 8 & 2.1 & [192] & {$[1,17,30,31]$} \\
\hline & $\mathrm{C}$ & Beads & 6.5 & 1.3 & [76] & \\
\hline & $\mathrm{R}$ & Flakes/Beads & 7 & $0.6-1.3$ & {$[33]$} & \\
\hline & $\mathrm{R} / \mathrm{C}$ & Flakes/Beads & 6.5 & 4.0 & [43] & \\
\hline & M & Flakes & & & & {$[12,123,138]$} \\
\hline \multirow[t]{2}{*}{$\mathrm{Pb}(\mathrm{II})$} & $\mathrm{R}$ & Flakes & 5 & 0.2 & {$[14]$} & {$[17,31]$} \\
\hline & M & Flakes & & & & {$[123,138]$} \\
\hline \multirow[t]{2}{*}{$\mathrm{Ni}(\mathrm{II})$} & M & Flakes & 2 & 2.0 & [120] & {$[138]$} \\
\hline & $\mathrm{R}$ & Flakes & & & & {$[50,87,120,140,141]$} \\
\hline \multirow[t]{2}{*}{$\mathrm{Hg}(\mathrm{II})$} & $\mathrm{R}$ & Flakes & & & & {$[142]$} \\
\hline & M & Flakes & & & & {$[88,130,161]$} \\
\hline \multirow[t]{2}{*}{$\mathrm{Cr}(\mathrm{III})$} & $\mathrm{R}$ & Flakes & 5 & 0.5 & {$[35]$} & [206] \\
\hline & M & Flakes & & & & [138] \\
\hline \multirow[t]{2}{*}{$\mathrm{U}(\mathrm{VI})$} & M & Flakes & $4 / 5 / 6$ & $1 / 1.8 / 2.7$ & {$[109,160]$} & [98] \\
\hline & $\mathrm{R}$ & Flakes & $4 / 5 / 6$ & 1/1.4/1.6 & {$[160]$} & {$[46,47,159]$} \\
\hline
\end{tabular}

Abbreviations: R, raw chitosan; M, chemically-modified chitosan; C, cross-linked chitosan; Membr., membrane; and Depos., chitosan deposited on a mineral membrane; Add. Ref., additional references on the metal sorption by chitosan materials without complete description of experimental conditions and/or sorption isotherms.

resins. More recently, Lasko and Hurt investigated silver recovery from effluents produced in photographic industry [169] using chitosan and compared sorption performance against synthetic resins. They observed that the biopolymer was competitive against conventional materials. Several derivatives of chitosan has been prepared with separative performances that appear greater than those reached with conventional processes $[65,203,245]$. For example, Inoue investigated the separation of rare earths using complexane types of modified chitosan and compared the separative performance to that obtained with a polyallylamine that was modified with the same kind of functional groups [245,246]. They showed that it was possible to achieve the separation of yttrium from samarium from bi-component mixtures and that of these rare earths from mixtures containing lanthanum, cerium, praseodymium and neodymium, while their separation by conventional materials was difficult. They conclude that the excellent separation behavior cannot be explained by the nature of the chelating functional groups grafted on chitosan but to the synergistic effect of these functional groups in combination with chitosan polymer matrix. This concept can be also applied for the preparation of molecular-imprinted chitosan derivatives $[66,72]$. Alam et al. $[65,203]$ obtained a very efficient recovery of rhodium at using molecular-imprinted chitosan while the recovery of this metal in the presence of other PGMs reveals difficult with conventional processes. Despite the large number of studies on metal ion interactions with chitosan for the last twenty years, chitosan sorbents 
Table 5

Summary table for the sorption capacities $\left(q_{\max }, \mathrm{mmol} \mathrm{Me}^{-1}\right)$ of some metal anions on chitosan-based materials

\begin{tabular}{|c|c|c|c|c|c|c|}
\hline Metal & Sorbent & Form & $\mathrm{pH}$ & $q_{\max }$ & Reference & Add. Ref. \\
\hline \multirow[t]{4}{*}{$\mathrm{Mo}(\mathrm{VI})$} & $\mathrm{R}$ & Flakes & 3 & $7-8$ & [42] & \multirow{4}{*}[20,24,42,45,166]{} \\
\hline & $\mathrm{R}$ & Beads & 3 & $7-8$ & [44] & \\
\hline & $\mathrm{C}$ & Flakes & 3 & $1-5$ & [42] & \\
\hline & $\mathrm{C}$ & Beads & 3 & $7-8$ & [44] & \\
\hline \multirow[t]{4}{*}{$\mathrm{V}(\mathrm{V})$} & $\mathrm{R}$ & Flakes & 3 & $7-8$ & [167] & \\
\hline & $\mathrm{R}$ & Beads & 3 & $7-8$ & [44] & \\
\hline & $\mathrm{C}$ & Flakes & 3 & $2-5$ & [44] & \\
\hline & $\mathrm{C}$ & Beads & 3 & $7-8$ & [44] & \\
\hline \multirow[t]{3}{*}{$\operatorname{Pd}(\mathrm{II})^{\mathrm{a}}$} & $\mathrm{C}$ & Flakes & 2 & 1.5 & [94] & \multirow[t]{3}{*}[18,87,121]{} \\
\hline & M & Flakes & 2 & 1.5 & [145] & \\
\hline & M & Beads & 2 & $2-4$ & {$[95]$} & \\
\hline \multirow[t]{3}{*}{$\mathrm{Pt}(\mathrm{IV})^{\mathrm{a}}$} & $\mathrm{C}$ & Flakes & 2 & 1.5 & [165] & \multirow[t]{3}{*}[18,87,121]{} \\
\hline & M & Flakes & 2 & 2 & [145] & \\
\hline & M & Beads & 2 & $2-3$ & {$[95]$} & \\
\hline $\mathrm{Au}(\mathrm{III})^{\mathrm{a}}$ & $\mathrm{C}, \mathrm{M}$ & Flakes & $3-4$ & $2-3$ & [146] & [104] \\
\hline \multirow[t]{3}{*}{$\mathrm{Cr}(\mathrm{VI})$} & $\mathrm{C}$ & Beads & 5.8 & 1.3 & [195] & \multirow{3}{*}{$\begin{array}{l}{[144]} \\
{[196,228]}\end{array}$} \\
\hline & $\mathrm{R}$ & Flakes & 2 & 0.6 & [196] & \\
\hline & $\mathrm{R}$ & Flakes & 4 & 0.5 & [15] & \\
\hline $\operatorname{As}(\mathrm{V})$ & M & Beads & $2-3$ & & & {$[144,256,257]$} \\
\hline $\mathrm{Se}(\mathrm{V})$ & M & Flakes & & & & [144] \\
\hline
\end{tabular}

Abbreviations: R, raw chitosan; M, chemically-modified chitosan; C, cross-linked chitosan, Membr., membrane; and Depos., chitosan deposited on a mineral membrane; Add. Ref., additional references on the metal sorption by chitosan materials without complete description of experimental conditions and/or sorption isotherms.

a Palladium, platinum and gold: chloropalladate, chloroplatinate and chloroaurate species, respectively.

have not been applied at the industrial scale. There are several reasons for explaining this difficulty in transferring the process to industrial applications such as: (a) stability of the polymer; (b) cost of raw material; (c) variability in the polymer characteristics; (d) production levels.

\subsection{Stability}

Being a biopolymer, chitosan is biodegradable. This property may be interesting for some applications such as the preparation of copper-chelates for the treatment of plant disease [247]. The progressive degradation of chitosan allows releasing copper, the active agent. However, it may also be a serious drawback for long-time applications in sorption processes. Indeed, sorbent recycling is necessary for making cost-efficient the use of chitosan for environmental applications; this may be difficult due to biopolymer biodegradation, especially wet gel materials (the dry- ing of the beads significantly decreases the biodegradability). This action of microorganisms will be also a crucial parameter in the case of chitosan use in the water-soluble form (for polymer-enhanced ultrafiltration processes). It is possible to reinforce the stability of the polymer to biodegradation; and cross-linking treatment has been shown to significantly improve polymer stability $[248,249]$. The recycling of the polymer is less important in the case of precious metals recovery since the cost of the target metal allows a single use of the polymer. The stability of the polymer against biodegradation is of great concern for application involving water-soluble forms of chitosan (polymer-enhanced ultrafiltration). The degradation of chitosan resulting from bacterial/fungal contamination, but also from acidic hydrolysis may lead to a significant decrease of polymer weight, which in turn limits the retention of the polymer. For sorption processes, the acidic hydrolysis may be also decreased by cross-linking treatments. 
Another important criterion to be taken into account concerns thermal effects on polymer stability. Compared to conventional resins, chitosan is less stable [250]. The polymer begins to loose water at $81^{\circ} \mathrm{C}$, the first exothermic effect appears at $311^{\circ} \mathrm{C}$; this peak corresponds to the first stage of pyrolysis (dehydration, depolymerization and decomposition of the acetylated and deacetylated units of the polymer) and results in a mass loss of approximately $30 \%$. The second stage in the pyrolysis (i.e. between 320 and $380^{\circ} \mathrm{C}$ ) represents between 8 and $14 \%$ of mass loss (depending on gas atmosphere). The third stage of the thermal degradation corresponds to temperature range between 380 and $480-530{ }^{\circ} \mathrm{C}$, mass loss being around $8 \%$. Finally, the last stage of the thermal degradation represents about $3 \%$ mass loss in nitrogen atmosphere and up to $20 \%$ in air atmosphere (oxidation of charred residue). In the first stages of the degradation (low temperature below $400^{\circ} \mathrm{C}$ ), FTIR analysis of pyrolysis products shows unsaturated materials, while at high temperature the degradation of glycopyranosic ring is achieved. The lower thermal stability of chitosan may be of great interest at the end of sorbent life cycle since it will decrease the energy required to destroy the polymer. Moreover, the products of the degradation are more environmental friendly than those produced during thermal degradation of conventional resins [251]. The substitution of new functional groups on chitosan may affect thermal stability. Actually, several studies have shown conflicting conclusions depending on the kind of grafted groups: in the case of mercaptan derivative, it was found that the chemical modification slightly increased the stability of glycopyranosic ring [250], while in the case of chitosan Schiff bases the grafting of aromatic aldehyde derivatives slightly decreased thermal stability [252]. In the case of metal-loaded chitosan, Sreenivasan [253] concludes that the thermal behavior depends on the nature of the metal. He observed that the structural alterations induced by the chelation process should alter the thermal stability of the complexes but the decomposition temperature was only very slightly increased compared to chitosan. Chelation is known to change the conformation of the chitosan polymer. Disturbance of the natural ordering of the polymer might be expected to lead to thermal instability, while the additional bridging through metal ion might be expected to lead to enhancement of thermal stability. He attributed the small increase in the decomposition temperature of the complexes to the combined effect of these antagonist effects.

Mechanical stability is another concern in the evaluation of sorbent applicability. Though chitosan in powder and flakes is relatively mechanically stable, the conditioning under the form of chitosan gel beads, for example, significantly changes mechanical stability. Despite the number of studies dealing with chitosan gel beads, their mechanical stability is significantly less documented. The beads are deformable under their raw form with interesting elastic properties. The cross-linking treatment with glutaraldehyde leads to the formation of relatively strong beads (personal observations) but the beads lose their elasticity and deformability (due to supplementary linkages between polymer chains); under strong pressure constraint the beads break and small granules are formed. This is a serious drawback for applications at large scale. Another possibility for reinforcing mechanical stability consists in drying the beads. However, as pointed out above, the drying step must be performed under strict control to avoid loosing diffusion properties (drying for example in the presence of saccharose). Some interesting studies performed on chitosan fibers shows how the post-treatment of chitosan members (with phosphate, phthalate ...) may contribute to improve mechanical properties [254].

\subsection{Price, availability and standardization of production parameters}

The industrial user can be additionally rebutted by some commercial external parameters related to the price of raw material that may limit the competitiveness of chitosan versus styrene-DVB conventional resins, especially when the process is targeted to the recovery of common heavy metals and for the treatment of large flow rates. For this reason the chitosan process seems to be more appropriate (a) for polishing treatment; (b) for specific treatments involving valuable metals; or (c) when chitosan is shown to be highly selective (compared to conventional processes, as pointed out above). The cost of raw material is partly controlled by the lack of large market that would imply the development of large-capacity production units (which would result in turn to a decrease of the cost of the material) and the competition in use for cosmetic and medical applications that require 
high quality chitosan with large added value [255]. There is also a need for a better standardization of production process to be able to prepare reproducible chitosan batches. Sorption properties are strongly controlled as pointed out above by the characteristics of chitosan. Changes in the specifications of the polymer may significantly change sorption performance and would required adaptation of process design that is not favorable to a wide spreading of chitosan-based technology.

For these reasons, it sounds that a greater attention should be paid to using these interaction properties of chitosan with metal ions for the preparation of new materials and for the design of new applications. Some examples are briefly presented in the following section.

\section{Use of metal-loaded chitosan for other applications}

\subsection{Specific sorption properties}

Metal-loaded sorbents may be used for complementary sorption processes, taking advantage of the ability of the metal loaded on chitosan to sorb other solutes. For example, in the case of molybdate-loaded chitosan beads, the chelating affinity of molybdate for arsenic has been used for the recovery of $\mathrm{As}(\mathrm{V})$ and As(III) from dilute solutions [256,257]. Two different processes have been used for the preparation of molybdate-impregnated chitosan beads: the sorption process [256], and the coagulation process [174]. The critical parameter is the strength of the chitosan-molybdate interaction, since it controls the release of molybdate during the arsenic sorption process. A partial release of molybdate in the solution leads to the formation of an arsenic-molybdate complex that is not adsorbable on chitosan. Therefore, arsenic sorption is decreased and there is a supplementary contamination of the solution with molybdate ions. This release effect is limited when molybdate-impregnated chitosan beads are treated with phosphoric acid: this pre-treatment enables the labile molybdate fraction to be removed from the beads. The coagulation process increases the stability of the molybdate on the beads. Under optimum experimental conditions, sorption capacities can reach up to $200 \mathrm{mg} \mathrm{As}^{-1}$ Mo. Since molybdate sorption capacity on the beads was close to $600 \mathrm{mg} \mathrm{Mog}^{-1}$ chitosan, this means a sorption capacity in excess of $100 \mathrm{mg} \mathrm{As} \mathrm{g}^{-1}$ sorbent at $\mathrm{pH}$ close to 3 [257].

Yoshizuka et al. prepared silver-loaded chitosan for the recovery of pesticides [258]. Indeed, some pesticides such as parathion bear sulfur functions that can interact with silver ions immobilized on the polymer support. Recently, Shi et al. [259] used silica coated with chitosan for the preparation of immobilized metal affinity support for the recovery of protein. These supports were characterized by their high stability in alkaline media and for repeated uses.

The preparation of magnetic chitosan gel beads $[43,260,261]$ offers interesting perspective for the treatment of metal containing slurries. Indeed, the magnetic behavior of the beads improves the feasibility of recovering the exhausted sorbent from highly loaded suspensions. This kind of magnetic particles have been used for the recovery of cadmium [43], and for dye sorption [261]. This coating procedure can be very helpful in designing new sorbing materials. Recent studies have shown the interest of embedding nano-particles with magnetic properties in polymer matrices for the recovery of toxic metals, such as arsenic [262,263]. This concept could be also applied with chitosan gel materials.

\subsection{Catalytic properties}

The development of catalytic processes based on precious and strategic metals (platinum group metals) has driven research into the design of supportedcatalysts in order to improve metal recovery at the end of catalytic reaction. As an alternative to activated carbon and alumina supports, a great deal of attention has been paid to the use of polymers for supporting catalytic metals [264]. Usually the interaction of the metal with the support is stronger than that found with conventional supports, moreover the structure of the polymer can add stereo-selectivity to the reaction [265]. Biopolymers are frequently cited as possible supports for enantioselective separations $[266,267]$ and chitosan has been used for the separation of optical isomers of amino acids [268]; moreover, the strong interactions of this biopolymer with metal ions can explain the recent studies concerning its utilization for supported catalysis. First references 
to chitosan-supported catalysis were cited in the early eighties by Arena [269-271] for the preparation of hydrogenation catalysts. More recently, chitosan-based catalysts were prepared for reactions as different as oxidation reactions [272-274], ring opening polymerization reactions [275], fine chemical synthesis [276-279], as well as reduction and hydrogenation reactions [280-286]. Esumi et al. [287] describe gold-chitosan nano-composites that can be used as anti-oxidant materials for the catalytic destruction of free radical oxygen species. A cobalt-loaded derivative of chitosan (CoSalen derivative of chitosan) was shown to be efficient at binding molecular oxygen reversibly and the material was used for the electrochemical reduction of oxygen to hydrogen peroxide, which may be used for the catalytic oxidation of organic molecules [288]. The versatility of the polymer may be used to manufacture special catalytic conditioning such as catalytic hollow fibers [289]. Chitosan could be also used as a surface coating preliminary to metal impregnation and catalyst conditioning: on mineral membranes, mineral powders, foams, porous materials for the treatment of liquid and gas streams.

\subsection{Miscellaneous}

The interaction of chitosan with metals and salts has been used for the manufacturing of solid-state polymer batteries and electronic devices [290-292]. Chitosan can be made into an ionic conductor by dissolution in acetic acid and the conductivity can be improved by adding monovalent ions (such as lithium acetate) to the acetic acid-chitosan solution. These electrochemical properties have also been used for the coating of glassy carbon electrodes and for the preparation of ion-selective electrodes, specially directed to the measurement of gold, silver, platinum and palladium in acidic solutions [293].

These properties have also been used for optical applications, for the manufacturing of optical wave-guiding chitosan thin films [294]. The casting of chitosan-acetic acid solutions containing rare-earth metals (such as $\mathrm{Er}^{3+}$ and $\mathrm{Nd}^{3+}$ ) allowed films to be prepared with a fixed refractive index (around 1.5), very low light absorption in the range $300-2700 \mathrm{~nm}$, and low loss of optical wave-guiding $\left(\sim 0.5 \mathrm{~dB} \mathrm{~cm}^{-1}\right)$. Yonezawa et al. discussed the effect of experimental parameters, especially the exposure to UV light of cast films made of chitosan (in acetic acid solutions) and gold, on the structure and aspect of the organo-metallic films [295,296]. They observed in selected conditions the formation of colloidal particles and (at long irradiation time) the formation of gold mirror surfaces. Chitosan acted as a stabilizer of gold colloidal particles issued from a photochemical reaction of gold salt at the surface of the polymer. These materials are promising intermediates for the manufacturing of electro-optical devices.

Chitosan gel membranes have been used for their separation properties for pervaporation or selective diffusion processes. Wang and Shen [297] investigated the effect of the addition of copper salts (chloride and nitrate) to the water/ethanol mixture on the pervaporation performance and directly correlated the change in separation properties to the interactions of the chitosan membrane with copper salts (ionic cross-linking). Kubota [298] prepared a chitosan-transition metal complex by casting acetic acid chitosan solutions onto a PTFE membrane, after drying at $40^{\circ} \mathrm{C}$ and treatment with $\mathrm{NaOH}$ solution $(1 \mathrm{M})$, rinsed membranes were immersed in transition metal solutions (sulfate salts of $\mathrm{Mn}, \mathrm{Fe}, \mathrm{Co}, \mathrm{Ni}, \mathrm{Cu}$ and $\mathrm{Zn}$ ). The metal-loaded membranes were used for the investigation of permeability properties using $\mathrm{KCl}$, sucrose and dipeptides as test molecules. Complexation with $\mathrm{Ni}^{2+}, \mathrm{Cu}^{2+}$ and $\mathrm{Zn}^{2+}$ significantly decreased permeability due to the formation of compact chitosan-metal complexes. In the case of $\mathrm{Mn}^{2+}, \mathrm{Fe}^{2+}$ and $\mathrm{Co}^{2+}$ the lability of the metal during the permation process resulted in the formation of holes in the membrane and led to an increase in the permeation rates, compared to reference material. Roughly, the permeability properties can be correlated to the molar ratio between glucosamine units and metal adsorbed, and to the swelling properties of the membrane.

Metal-loaded chitosan can also be applied in agriculture field for the manufacturing of plant disease curing preparations. Recently, copper chelated on chitosan has been successfully used for the treatment of plant disease [247]: the progressive release of copper from chitosan preparation allows reducing the amount of copper to be spread on the plant and avoids soil contamination (by the release of metal in excess). Metal release seems to have a synergistic effect with the elicitor effect of chitosan (for the activation of chitosanase, which is active as an anti-fungi protective agent). 


\section{Conclusions}

Chitosan is very efficient at sorbing metal cations by chelation at near neutral $\mathrm{pH}$ and metal anions by electrostatic attraction to protonated amine groups in acidic solutions. It can readily be modified physically and/or chemically to enhance diffusion properties (improving kinetic rates, enhancing the accessibility to sorption sites ...), to improve sorption selectivity, to change sorption mechanisms, to enlarge $\mathrm{pH}$ range for optimum sorption, or to reduce the effect of the solution matrix.

The polymer can be used in a water soluble form in polymer ultrafiltration processes, in flake or gel-bead form for sorption in batch or fixed-bed column systems, or deposited on a suitable support (glass beads, ceramics ...). The main controlling parameters are the diffusion properties (in relation with crystalline properties), which can be partially controlled by adjusting the particle size or polymer conditioning. Sorption is also frequently controlled by the speciation of metal ions in solution (in relation with $\mathrm{pH}$, metal concentration and composition of the solution, including the presence of chelating agents, ligands, etc.).

These high sorption capacities for metal ions can be of great use for the recovery of valuable metals or the treatment of contaminated effluents, and the loading of the polymer matrix with metal can give the support interesting complementary properties for the sorption of other organic or inorganic materials, for catalytic applications and for the manufacturing of new optical and electronic devices.

\section{Acknowledgements}

I acknowledge the constant contribution of Thierry Vincent (Ecole des Mines d'Alès) to this research program. Thanks are due to the different groups that were involved in our research program on metal ion sorption by chitosan-based sorbents: Dr. Ricardo Navarro and Dr. Imelda Saucedo from Universidad de Guanajuato (Mexico); Dr. Ana Sastre and Dr. Montserrat Ruiz from Universidad Politecnica de Catalunya (Spain); Dr. Malgorzata Jaworska from Warsaw University of Technology (Poland); Dr. John Tobin from Dublin City University (Ireland); Mrs Martha Ly Arrascue from Universidad Peruana Cayetano Heredia de Lima
(Peru). I also thank the Ph.D. students that were involved in this research: Marielle Jansson-Charrier, Céline Milot, Laurent Dambies, Javier Guzman, Philippe Chassary, Eko Prasetyo Kuncoro, and Francisco Peirano Blondet. The research grants given by the French Ministry of Industry, the Franco-Peruvian collaboration program (Réseau Raul Porras Barrenechea) and the Franco-Mexican program of collaboration (PCP) are gratefully acknowledged. Financial supports by European Union for student exchanges (Leonardo Program) and for research program (3SPM project in the frame of Growth program) are also gratefully acknowledged.

\section{References}

[1] A.K. Bhattacharya, C. Venkobachar, J. Environ. Eng. 110 (1984) 110.

[2] S.E. Bailey, T.J. Olin, R.M. Bricka, D.A. Adrian, Water Res. 33 (1999) 2469.

[3] B. Volesky, Z.R. Holan, Biotechnol. Prog. 11 (1995) 235.

[4] M. Tsezos, B. Volesky, Biotechnol. Bioeng. 24 (1982) 385.

[5] M. Tsezos, B. Volesky, Biotechnol. Bioeng. 24 (1982) 955.

[6] A.J. Michell, G. Scurfield, Arch. Biochem. Biophys. 120 (1967) 628.

[7] D.S. Wales, B.F. Sagar, J. Chem. Tech. Biotechnol. 49 (1990) 345.

[8] E. Guibal, C. Roulph, P. Le Cloirec, Environ. Sci. Technol. 29 (1995) 2496.

[9] B.J. Mcafee, W.D. Gould, J.C. Nadeau, A.C.A. da Costa, Sep. Sci. Technol. 36 (2001) 3207.

[10] W.Y. Baik, J.H. Bae, K.M. Cho, W. Hartmeier, Biores. Technol. 81 (2002) 167.

[11] O. Gyliene, R. Rekertas, M. Salkauskas, Water Res. 36 (2002) 4128

[12] M.S. Masri, V.G. Randall, A.G. Pittman (Eds.), Division of Polymer Chemistry (A.C.S.), Polymer Preprints, vol. 19, American Chemical Society, NY, 1978, pp. 483-488.

[13] G. McKay, H.S. Blair, A. Findon, in: H. Eccles, S. Hunt (Eds.), Immobilisation of Ions by Bio-Sorption, Ellis Horwood, Ltd., Chichester, UK, 1986, pp. 59-69.

[14] C.A. Eiden, C.A. Jewell, J.P. Wightman, J. Appl. Polym. Sci. 25 (1980) 1587.

[15] P. Udaybhaskar, L. Iyengar, A.V.S. Prabhakara Rao, J. Appl. Polym. Sci. 39 (1990) 739.

[16] R. Bassi, S.O. Prasher, B.K. Simpson, Environ. Technol. 20 (1999) 1177.

[17] R. Bassi, S.O. Prasher, B.K. Simpson, Sep. Sci. Technol. 35 (2000) 547.

[18] K. Inoue, T. Yamaguchi, M. Iwasaki, K. Ohto, K. Yoshizuka, Sep. Sci. Technol. 30 (1995) 2477.

[19] Y. Tang, B. Chen, S. Mo, Talanta 43 (1996) 761.

[20] S. Hoshi, K. Konuma, K. Sugawara, M. Uto, K. Akatsura, Talanta 44 (1997) 1473. 
[21] S. Hoshi, K. Konuma, K. Sugawara, M. Uto, K. Akatsuka, Talanta 47 (1998) 659.

[22] H. Minamisawa, N. Arai, T. Okutani, Anal. Si. 15 (1999) 269.

[23] Y.H. Gao, K.H. Lee, M. Oshima, S. Motomizu, Anal. Sci. 16 (2000) 1303.

[24] R.A.A. Muzzarelli, R. Rocchetti, Anal. Chim. Acta 64 (1973) 371.

[25] G.A.F. Roberts, Chitin Chemistry, MacMillan, London, UK, 1992, 350p.

[26] D. Knorr, J. Food Sci. 48 (1983) 36.

[27] G.G. Maghami, G.A.F. Roberts, Makromol. Chem. 189 (1988) 2239.

[28] H. Yoshida, A. Okamoto, T. Kataoka, Chem. Eng. Sci. 48 (1993) 2267

[29] G. Gibbs, J.M. Tobin, E. Guibal, J. Appl. Polym. Sci. 90 (2003) 1073.

[30] N. Jha, L. Iyengar, A.V.S. Prabhakara Rao, J. Environ. Eng. 114 (1988) 962.

[31] M. Gonzalez-Davila, J.M. Santana-Casiano, F.J. Millero, J. Colloid Interf. Sci. 137 (1990) 102.

[32] O.A.C.J. Monteiro, C. Airoldi, J. Colloid Interf. Sci. 212 (1999) 212

[33] M.S. Dzul Erosa, T.I. Saucedo Medina, R. Navarro Mendoza, M. Avila Rodriguez, E. Guibal, Hydrometallurgy 61 (2001) 157.

[34] B. Benguella, H. Benaissa, Colloids Surf. A: Physicochem. Eng. Aspects 201 (2002) 142.

[35] R. Maruca, B.J. Suder, J.P. Wightman, J. Appl. Polym. Sci. 27 (1982) 4827.

[36] K.J. Vårum, M.W. Antohonsen, H. Grasdalen, O. Smidsrød, Carbohydr. Res. 211 (1991) 17.

[37] K.J. Vårum, B. Egelandsdal, M.R. Ellekjær, Carbohydr. Polym. 28 (1995) 187.

[38] M.H. Ottøy, K.J. Vårum, O. Smidsrød, Carbohydr. Polym. 29 (1996) 17.

[39] M.L. Duarte, M.C. Ferreira, M.R. Marvão, J. Rocha, Int. J. Biol. Macromol. 31 (2002) 1.

[40] K. Ogawa, T. Yui, Biosci. Biotech. Biochem. 57 (1993) 1466.

[41] K. Okuyama, K. Noguchi, T. Miyazawa, T. Yui, K. Ogawa, Macromolecules 30 (1997) 5849.

[42] C. Milot, J. McBrien, S. Allen, E. Guibal, J. Appl. Polym. Sci. 68 (1998) 571.

[43] G.L. Rorrer, T.-Y. Hsien, J.D. Way, Ind. Eng. Chem. Res. 32 (1993) 2170.

[44] E. Guibal, C. Milot, J.M. Tobin, Ind. Eng. Chem. Res. 37 (1998) 1454.

[45] E. Guibal, C. Milot, J. Roussy, Wat. Environ. Res. 71 (1999) 10.

[46] E. Piron, M. Accominotti, A. Domard, Langmuir 13 (1997) 1653.

[47] E. Piron, A. Domard, Int. J. Biol. Macromol. 21 (1997) 327.

[48] G. McKay, H.S. Blair, S. Grant, J. Appl. Polym. Sci. 40 (1987) 63.

[49] I.M. van der Lubben, J.C. Verhoef, G. Borchard, H.E. Junginger, in: R.A.A. Muzzarelli (Ed.), Chitosan per os from
Dietary Supplement to Drug Carrier, ATEC, Grottammare, Italy, 2000, pp. 115-126.

[50] T. Mitani, C. Nakajima, I.E. Sungkono, H. Ishii, J. Environ. Sci. Health Part A 30 (1995) 669.

[51] T.-Y. Hsien, G.L. Rorrer, Sep. Sci. Technol. 30 (1995) 2455.

[52] Y. Kawamura, H. Yoshida, S. Asai, H. Tanibe, J. Chem. Eng. Jpn. 31 (1998) 1.

[53] W.S. Wan Ngah, C.S. Endud, R. Mayanar, React. Funct. Polym. 50 (2002) 181.

[54] R.A.A. Muzzarelli, F. Tanfani, M. Emanuelli, S. Gentile, J. Appl. Biochem. 2 (1980) 380.

[55] Z. Modrzejewska, W. Kaminski, Ind. Eng. Chem. Res. 38 (1999) 4946.

[56] X.P. Wang, Z.Q. Shen, Polym. Int. 49 (2000) 1426.

[57] F.-L. Mi, S.-S. Shyu, Y.-B. Wu, S.-T. Lee, J.-Y. Shyong, R.-N. Huang, Biomaterials 22 (2001) 165.

[58] E.B. Denkbas, M. Odabasi, J. Appl. Polym. Sci. 76 (2000) 1637.

[59] M. Amaike, Y. Senoo, H. Yamamoto, Macromol. Rapid Commun. 19 (1998) 287.

[60] O.C. Agboh, Y. Quin, Polym. Adv. Technol. 8 (1997) 355.

[61] T. Vincent, E. Guibal, Solvent Extr. Ion Exch. 18 (2000) 1241.

[62] T. Vincent, E. Guibal, Ind. Eng. Chem. Res. 40 (2001) 1406.

[63] M.A. Ruiz, A.M. Sastre, E. Guibal, Sep. Sci. Technol. 37 (2002) 2143.

[64] K. Inoue, H. Hirakawa, Y. Ishikawa, T. Yamaguchi, J. Nagata, K. Ohto, K. Yoshizuka, Sep. Sci. Technol. 31 (1996) 2273.

[65] M.S. Alam, K. Inoue, K. Yoshizuka, Hydrometallurgy 49 (1998) 213.

[66] Y. Baba, K. Masaaki, Y. Kawano, React. Funct. Polym. 36 (1998) 167.

[67] T.W. Tan, X.J. He, W.X. Du, J. Chem. Tech. Biotechnol. 76 (2001) 191.

[68] Z. Cao, H. Ge, S. Lai, Eur. Polym. J. 37 (2001) 2141.

[69] K. Kurita, Prog. Polym. Sci. 26 (2001) 1921.

[70] K. Inoue, Y. Baba, J. Ion Exch. 8 (1997) 115.

[71] K. Inoue, K. Yoshizuka, Y. Baba, J. Ion Exch. 8 (1997) 180.

[72] Y. Baba, K. Inoue, J. Ion Exch. 8 (1997) 227.

[73] K. Inoue, K. Ohto, Y. Baba, J. Ion Exch. 9 (1998) 115.

[74] T. Becker, M. Schlaak, H. Strasdeit, React. Funct. Polym. 44 (2000) 289.

[75] G.K. Moore, G.A.F. Roberts, Int. J. Biol. Macromol. 3 (1981) 337.

[76] T.-Y. Hsien, G.L. Rorrer, Ind. Eng. Chem. Res. 36 (1997) 3631.

[77] O.A.C.J. Monteiro, C. Airoldi, Int. J. Biol. Macromol. 26 (1999) 119.

[78] F.-L. Mi, C.-Y. Kuan, S.-S. Shyu, S.-T. Lee, S.-F. Chang, Carbohydr. Polym. 41 (2000) 389.

[79] M. Ruiz, A.M. Sastre, E. Guibal, React. Funct. Polym. 45 (2000) 155

[80] D. Capitani, A.A. De Angelis, V. Crescenzi, G. Masci, A.L. Segre, Carbohydr. Polym. 45 (2001) 245.

[81] G. Paradossi, F. Cavalieri, V. Crescenzi, Carbohydr. Res. 300 (1997) 77. 
[82] V. Crescenzi, G. Paradossi, P. Desideri, M. Dentini, F. Cavalieri, E. Amici, R. Lisi, Polym. Gels Ntwk. 5 (1997) 225.

[83] Y. Kawamura, M. Mitsushashi, H. Tanibe, H. Yoshida, Ind. Eng. Chem. Res. 32 (1993) 386.

[84] Y. Kawamura, H. Yoshida, S. Asai, H. Tanibe, Wat. Sci. Technol. 35 (1997) 97.

[85] R.-S. Juang, C.-Y. Ju, Ind. Eng. Chem. Res. 36 (1997) 5403.

[86] R.-S. Juang, C.-Y. Ju, Ind. Eng. Chem. Res. 37 (1998) 3463.

[87] K. Inoue, Y. Baba, K. Yoshizuka, Bull. Chem. Soc. Jpn. 66 (1993) 2915.

[88] K. Ohga, Y. Kurauchi, H. Yanase, Bull. Chem. Soc. Jpn. 60 (1987) 444.

[89] F.-L. Mi, S.-S. Shyu, T.-B. Wong, S.-F. Jang, S.-T. Lee, K.-T. Lu, J. Appl. Polym. Sci. 74 (1999) 1093.

[90] F.-L. Mi, S.-S. Shyu, S.-T. Lee, T.-B. Wong, J. Polym. Sci. Part B. Polym. Phys. 37 (1999) 1551.

[91] S.-T. Lee, F.-L. Mi, Y.-J. Shen, S.-S. Shyu, Polymer 42 (2001) 1879.

[92] K. Kurita, Y. Koyama, A. Taniguchi, J. Appl. Polym. Sci. 31 (1986) 1169.

[93] K. Kurita, Y. Koyama, A. Taniguchi, J. Appl. Polym. Sci. 31 (1986) 1951.

[94] M. Ruiz, A.M. Sastre, E. Guibal, React. Funct. Polym. 45 (2000) 155.

[95] M. Ruiz, A.M. Sastre, E. Guibal, Sep. Sci. Technol. 37 (2002) 2385.

[96] K. Sreenivasan, J. Appl. Polym. Sci. 69 (1998) 1051.

[97] T. Tojima, H. Katsura, M. Nishiki, S. Tokura, N. Sakairi, Carbohydr. Polym. 40 (1999) 17.

[98] P.L. Lopez-de Alba, B. Urbina, J.C. Alvarado, G.A. Andreu, J.A. Lopez, J. Radioanal. Nucl. Chem. Lett. 118 (1987) 99.

[99] K.R. Holme, L.D. Hall, Can. J. Chem. 69 (1991) 585.

[100] R.A.A. Muzzarelli, F. Tanfani, Pure Appl. Chem. 54 (1982) 2141.

[101] S. Tokura, S.-I. Nishimura, N. Nishi, Polymer J. 15 (1983) 597.

[102] R.A.A. Muzzarelli, Carbohydr. Polym. 8 (1988) 1.

[103] L.-G. Tang, D.N.-S. Hon, J. Appl. Polym. Sci. 79 (2001) 1476.

[104] W.S. Wan Ngah, K.H. Liang, Ind. Eng. Chem. Res. 38 (1999) 1411.

[105] R.A.A. Muzzarelli, F. Tanfani, M. Emanuelli, Carbohydr. Polym. 4 (1984) 137.

[106] R.A.A. Muzzarelli, F. Tanfani, M. Emanuelli, Biotechnol. Bioeng. 27 (1985) 1115.

[107] R.A.A. Muzzarelli, Carbohydr. Polym. 5 (1985) 85.

[108] R.A.A. Muzzarelli, A. Zattoni, Int. J. Biol. Macromol. 8 (1986) 137.

[109] I. Saucedo, E. Guibal, C. Roulph, P. Le Cloirec, Environ. Technol. 13 (1992) 1101.

[110] M. Gomez-Guillén, A. Gomez-Sanchez, M.-E. MartinZamora, Carbohydr. Res. 233 (1992) 255.

[111] M. Gomez-Guillén, A. Gomez-Sanchez, M.-E. MartinZamora, Carbohydr. Res. 258 (1994) 313.

[112] T. Seo, T. Iijima, in: C.G. Gebelein (Ed.), Biotechnology and Polymers, Plenum Press, NY, 1991, pp. 215-227.
[113] Y. Shigemasa, H. Usui, M. Morimoto, H. Saimoto, Y. Okamoto, S. Minami, H. Sahiwa, Carbohydr. Polym. 39 (1999) 237.

[114] C. Peng, Y. Wang, Y. Tang, J. Appl. Polym. Sci. 70 (1998) 501.

[115] S. Tan, Y. Wang, C. Peng, Y. Tang, J. Appl. Polym. Sci. 71 (1999) 2069.

[116] Z. Yang, Y. Wang, Y. Tang, J. Appl. Polym. Sci. 74 (1999) 3053.

[117] K. Inoue, K. Yoshizuka, Y. Baba (Eds.), New developments in ion exchange. Materials, fundamentals, and applications, in: Proceedings of the International Conference on Ion Exchange, ICIE'91, Tokyo, Japan, Kodansha, Ltd., 1991, pp. 543-548.

[118] K. Inoue, K. Yoshizuka, Y. Baba, in: C. Gebelein, C. Carraher (Eds.), Biotechnology and Bioactive Polymers, Plenum Press, New York, 1994, pp. 35-41.

[119] K. Inoue, K. Ohto, K. Yoshizuka, R. Shinbaru, K. Kina, Bunseki Kagaku 44 (1995) 283.

[120] S. Nagib, K. Inoue, T. Yamaguchi, T. Tamaru, Hydrometallurgy 51 (1999) 73.

[121] Y. Baba, H. Hirakawa, Chem. Lett. (1992) 1905.

[122] C.A. Rodrigues, M.C.M. Laranjeira, V.T. de Favere, E. Stadler, Polymer 39 (1998) 5121.

[123] D.W. Kang, H.R. Choi, D.K. Kweon, J. Appl. Polym. Sci. 73 (1999) 469.

[124] T. Sakaguchi, T. Horikoshi, A. Nakajima, Nippon Nôgeigaku Kaishi 53 (1979) 149.

[125] N. Nishi, A. Ebina, S.-I. Nishimura, A. Tsutsumi, O. Hasegawa, S. Tokura, Int. J. Biol. Macromol. 8 (1986) 311.

[126] N. Nishi, Y. Maekita, S.-I. Nishimura, O. Hasegawa, S. Tokura, Int. J. Biol. Macromol. 9 (1987) 109.

[127] K.S. Choi, H.S. Ahn, Polym. Korea 14 (1990) 516.

[128] A. Heras, N.M. Rodriguez, V.M. Ramos, E. Agullo, Carbohydr. Polym. 44 (2001) 1.

[129] V.M. Ramos, N.M. Rodriguez, M.S. Rodriguez, A. Heras, E. Agullo, Carbohydr. Polym. 51 (2003) 425.

[130] W. Argüelles-Monal, C. Peniche-Covas, Angew. Macromol. Chem. 207 (1993) 1.

[131] C. Ni, Y. Xu, J. Appl. Polym. Sci. 59 (1996) 499.

[132] E. Guibal, T. Vincent, R. Navarro Mendoza, J. Appl. Polym. Sci. 75 (2000) 119.

[133] T. Asakawa, K. Inoue, T. Tanaka, Kagaku, Kogaku Ronbunshu 26 (2000) 321.

[134] G. Cárdenas, P. Orlando, T. Edelio, Int. J. Biol. Macromol. 28 (2001) 167.

[135] E. Guibal, N. Van Offenberg Sweeney, T. Vincent, J.M. Tobin, React. Funct. Polym. 50 (2002) 149.

[136] M. Ruiz, A.M. Sastre, E. Guibal, Solvent Extr. Ion Exch. 21 (2003) 307.

[137] R.A.A. Muzzarelli, F. Tanfani, S. Gentile, M. Emanuelli, Carbohydr. Res. 104 (1982) 235.

[138] M. Weltrowski, B. Martel, M. Morcellet, J. Appl. Polym. Sci. 59 (1996) 647.

[139] K. Kondo, S. Nakagawa, M. Matsumoto, T. Yamashita, I. Furukawa, J. Chem. Eng. J. 30 (1997) 846. 
[140] J.M. Randall, V.G. Randall, G.M. McDonald, R.N. Young, M.S. Masri, J. Appl. Polym. Sci. 23 (1979) 727.

[141] G. McKay, H.S. Blair, A. Findon, Indian J. Chem. 28A (1989) 356

[142] C. Peniche-Covas, L.W. Alvarez, W. Argüelles-Monal, J. Appl. Polym. Sci. 46 (1992) 1147.

[143] M.T. Vasconcelos, M.F. Leal, H.M.V.M. Soares, Anal. Chim. Acta 330 (1996) 273

[144] S. Qian, G. Huang, J. Jiang, F. He, Y. Wang, J. Appl. Polym. Sci. 77 (2000) 3216.

[145] E. Guibal, M. Ruiz, T. Vincent, A. Sastre, R. Navarro Mendoza, Sep. Sci. Technol. 36 (2001) 1017.

[146] M. Ly Arrascue, H. Maldonado Garcia, O. Horna, E. Guibal, in: V.S.T. Ciminelli, O. Garcia, Jr. (Eds.), Biohydrometallurgy: Fundamentals, Technology and Sustainable Development, vol. 11B, Elsevier, Amsterdam, 2001, pp. 119-128.

[147] R.G. Pearson, J. Am. Chem. Soc. 85 (1963) 3533.

[148] Y. Marcus, Ion Properties, Marcel Dekker Inc., New York, NY, 1997, 259p.

[149] S. Schlick, Macromolecules 19 (1986) 192.

[150] M. Rhazi, J. Desbrières, A. Tolaimate, M. Rinaudo, P. Vottero, A. Alagui, Polymer 43 (2002) 1267.

[151] J.W. Park, M.-O. Park, K.K. Park, Bull. Kor. Chem. Soc. 5 (1984) 108.

[152] J.M. Nieto, C. Peniche-Covas, J. Del Bosque, Carbohydr. Polym. 18 (1987) 221.

[153] A. Domard, Int. J. Biol. Macromol. 9 (1987) 98.

[154] E. Chiessi, G. Paradossi, M. Venanzi, B. Pispisa, J. Inorg. Biochem. 46 (1992) 109.

[155] S.C. Bahtia, N. Ravi, Biomacromolecules 1 (2000) 413.

[156] M. Shahgholi, J.H. Callahan, B.J. Rappoli, D.A. Rowley, J. Mass Spectrom. 32 (1997) 1080.

[157] J.W. Park, K.-H. Choi, K.K. Park, Bull. Korean Chem. Soc. 4 (1983) 68.

[158] S. Hirano, Y. Kondo, Y. Nakazawa, Carbohydr. Res. 100 (1982) 431.

[159] E. Piron, A. Domard, Int. J. Biol. Macromol. 22 (1998) 33.

[160] E. Guibal, I. Saucedo, J. Roussy, P. Le Cloirec, React. Polym. 23 (1994) 147.

[161] M.L. Ferreira, M.E. Gschaider, Macromol. Biosci. 1 (2001) 233.

[162] A. Debbaudt, M. Zalba, M.L. Ferreira, M.E. Gschaider, Macromol. Biosci. 1 (2001) 249.

[163] N.C. Braier, R.A. Jishi, J. Mol. Struct.: Theochem. 499 (2000) 51.

[164] P. Sorlier, A. Denuzière, C. Viton, A. Domard, Biomacromolecules 2 (2001) 765.

[165] E. Guibal, T. Vincent, A. Larkin, J.M. Tobin, Ind. Eng. Chem. Res. 38 (1999) 4011.

[166] E. Guibal, C. Milot, J. Roussy, Sep. Sci. Technol. 35 (2000) 1021.

[167] J. Guzman, I. Saucedo, J. Revilla, R. Navarro, E. Guibal, Langmuir 18 (2002) 1567.

[168] M. Ly Arrascue, H. Maldonado Garcia, O. Horna, E. Guibal, Hydrometallurgy 71 (2003) 191.
[169] C.L. Lasko, M.P. Hurst, Environ. Sci. Technol. 33 (1999) 3622.

[170] R.A.A. Muzzarelli, Natural Chelating Polymers, Pergamon, Oxford, UK, 1973, 254p.

[171] K.-D. Vorlop, J. Klein, Biotechnol. Lett. 3 (1981) 9.

[172] K.I. Draget, K.M. Varum, E. Moen, H. Gynnild, O. Smidsrod, Biomaterials 13 (1992) 635.

[173] H.P. Brack, S.A. Tirmizi, W.M.J. Risen, Polymer 38 (1997) 2351.

[174] L. Dambies, T. Vincent, A. Domard, E. Guibal, Biomacromolecules 2 (2001) 1198.

[175] L. Dambies, C. Guimon, S. Yiacoumi, E. Guibal, Colloids Surf. A: Physicochem. Eng. Aspects 177 (2001) 203.

[176] E. Guibal, J. Roussy, P. Le Cloirec, Water S.A. 22 (1996) 19.

[177] S. Demarger, A. Domard, Carbohydr. Res. 27 (1995) 101.

[178] E. Piron, A. Domard, Int. J. Biol. Macromol. 23 (1998) 113.

[179] C. Tien, Adsorption Calculations and Modeling, Butterworth-Heinemann, Newton, MA, 1994, 244p.

[180] G. McKay, Y.S. Ho, J.C.Y. Ng, Sep. Purif. Meth. 28 (1999) 87.

[181] J.C.Y. Ng, W.H. Cheung, G. McKay, J. Colloid Interf. Sci. 255 (2002) 64.

[182] D.G. Kinniburgh, Environ. Sci. Technol. 20 (1986) 895.

[183] S. Yiacoumi, C. Tien, Kinetics of Metal Adsorption from Aqueous Solutions, Kluwer Academic Publishers, Norwell, MA, 1995, 256p.

[184] J. Chen, F. Tendeyong, S. Yiacoumi, Environ. Sci. Technol. 31 (1997) 1433.

[185] C. Stöhr, J. Horst, W.H. Höll, React. Funct. Polym. 49 (2001) 117.

[186] C. Jeon, W.H. Höll, Hydrometallurgy (2003), in press.

[187] M. Gonzalez-Davila, F.J. Millero, Geochim. Cosmochim. Acta 54 (1990) 761.

[188] A. Esposito, F. Pagnanelli, A. Lodi, C. Solisio, F. Veglio, Hydrometallurgy 60 (2001) 129.

[189] R.-S. Juang, H.-J. Shao, Water Res. 36 (2002) 2999.

[190] K.H. Chu, J. Hazard. Mater. B90 (2002) 77.

[191] F. Pagnanelli, A. Esposito, L. Toro, F. Veglio, Water Res. 37 (2003) 627.

[192] J.R. Evans, W.G. Davids, J.D. MacRae, A. Amirbahman, Water Res. 36 (2002) 3219.

[193] A. Findon, G. McKay, H.S. Blair, J. Environ. Sci. Health Part A 28 (1993) 173.

[194] M. Jansson-Charrier, E. Guibal, J. Roussy, B. Delanghe, P. Le Cloirec, Water Res. 30 (1996) 465.

[195] S. Bosinco, E. Guibal, J. Roussy, P. Le Cloirec, Min. Pro. Ext. Met. Rev. 19 (1998) 277.

[196] Y. Sag, Y. Aktay, Process Biochem. 36 (2000) 157.

[197] G. McKay, V.J.P. Poots, J. Chem. Technol. Biotechnol. 30 (1980) 279.

[198] H.W. Jannasch, B.D. Honeyman, J.W. Murray, Limnol. Oceanogr. 41 (1996) 82.

[199] W.J. Weber, Jr., F.A. DiGiano, Process Dynamics in Environmental Systems, Wiley, New York, NY, 1996, 943p.

[200] J. Crank, The Mathematics of Diffusion, Oxford University Press, Oxford, UK, 1975, 414p. 
[201] Y.S. Ho, C.Y. Ng, G. McKay, Sep. Purif. Meth. 29 (2000) 189.

[202] J.J. Lenhart, L.A. Figueroa, B.D. Honeyman, D. Kaneko, Colloids Surf., A. Physicochem. Eng. Aspects 120 (1997) 243.

[203] M.S. Alam, K. Inoue, K. Yoshizuka, H. Ishibashi, Sep. Sci. Technol. 33 (1998) 655.

[204] M. Rhazi, J. Desbrières, A. Tolaimate, M. Rinaudo, P. Vottero, A. Alagui, M. El Meray, Eur. Polym. J. 38 (2002) 1523.

[205] R.W. Coughlin, M.R. Deshaies, E.M. Davis, Environ. Prog. 9 (1990) 35.

[206] V.W.D. Chui, K.W. Mok, C.Y. Ng, B.P. Luong, K.K. Ma, Environ. Int. 22 (1996) 463.

[207] C. Milot, Adsorption de Molybdate VI sur Billes de Gel de Chitosane-Application au Traitement d'Effluents Molydifères, Ph.D., Unité doctorale "Mécanique des Matériaux, Structures et Génie des Procédés"-Laboratoire d'accueil: Laboratoire Génie de 1'Environnement Industriel (Ecole des Mines d'Alès), 1998, 214 p.

[208] K. Kurita, T. Sannan, Y. Iwakura, J. Appl. Polym. Sci. 23 (1979) 511.

[209] K. Kurita, S. Chikaoka, Y. Koyama, Polym. J. 20 (1988) 1083.

[210] K. Kurita, S. Chikaoka, Y. Koyama, Chem. Lett. (1988) 9.

[211] E. Guibal, C. Milot, O. Eterradossi, C. Gauffier, A. Domard, Int. J. Biol. Macromol. 24 (1999) 49.

[212] M. Jaworska, K. Sakurai, P. Gaudon, E. Guibal, Polym. Int. 52 (2003) 198.

[213] M. Jaworska, K. Kula, P. Chassary, E. Guibal, Polym. Int. 52 (2003) 206.

[214] E. Guibal, M. Jansson-Charrier, I. Saucedo, P. Le Cloirec, Langmuir 11 (1995) 591.

[215] R.-S. Juang, H.-C. Lin, J. Chem. Tech. Biotechnol. 62 (1995) 141.

[216] G.C. Steenkamp, K. Keizer, H.W.J.P. Noeomagus, H.M. Krieg, J. Membr. Sci. 197 (2002) 147.

[217] X.D. Liu, S. Tokura, N. Nishi, N. Sakairi, Polymer 44 (2003) 1021.

[218] F.-C. Wu, R.-L. Tseng, R.-S. Juang, Ind. Eng. Chem. Res. 38 (1999) 270.

[219] R.-S. Juang, L.-D. Shiau, Ind. Eng. Chem. Res. 37 (1998) 555.

[220] I.M.N. Vold, K.M. Varum, E. Guibal, O. Smidsrod, Carbohydr. Polym. 84 (2003) 471.

[221] K.E. Geckeler, K. Volchek, Environ. Sci. Technol. 30 (1996) 725 .

[222] B.L. Rivas, E. Pereira, I. Moreno-Villoslada, Prog. Polym. Sci. 28 (2003) 173.

[223] S. Taha, P. Bouvet, G. Corre, G. Dorange, in: G.A.F. Roberts (Eds.), Study and modelisation of some heavy metals removal by ultrafiltration in presence of soluble chitosan, in: Proceedings of the European Chitin Society, Brest, France, Jacques André Publishers, Lyon, France, 1995, pp. 389-398.

[224] R.-S. Juang, R.-C. Shiau, J. Membr. Sci. 165 (2000) 159.

[225] E.K. Kuncoro, T. Lehtonen, J. Roussy, E. Guibal, in: P. Le Cloirec (Eds.), Polymer-enhanced ultrafiltration as a tool for metal ion recovery: case of mercury, in: Proceedings of the 5th I.W.A. Chemical Industry Group Conference, Nimes, France, November 13-15, 2002, I.W.A., London, UK, 2002, pp. 409-416.

[226] E.K. Kuncoro, T. Lehtonen, J. Roussy, E. Guibal, in M. Tsezos (Eds.), Mercury removal by polymer-enhanced ultrafiltration using chitosan as the macroligand, in: Proceedings of the International Biohydrometallurgy Symposium 2003, I.B.S.'03, Athens, Greece, 2003, in press.

[227] M. Jansson-Charrier, E. Guibal, J. Roussy, R. Surjous, P. Le Cloirec, Wat. Sci. Technol. 34 (1996) 169.

[228] K. Sag, Y. Aktay, Process Biochem. 36 (2001) 1187.

[229] M. Ruiz, A. Sastre, M.C. Zikan, E. Guibal, J. Appl. Polym. Sci. 81 (2001) 153.

[230] M. Jansson-Charrier, Biosorption d'ions métalliques (uranium et vanadium) sur chitosane, Ph.D., SPI-Academic Unit "Mécanique des Matériaux, Structures et Génie des Procédés"-Laboratoire d'accueil: Laboratoire Génie de l'Environnement Industriel (Ecole des Mines d'Alès), 1996, $222 \mathrm{p}$.

[231] R.A.A. Muzzarelli, Ion Exch. Membr. 1 (1974) 193.

[232] S. Sengupta, A.K. SenGupta, Colloids Surf. A. 191 (2001) 79.

[233] B. Krajewska, A. Olech, Polym. Gels Ntwk. 4 (1996) 33.

[234] B. Krajewska, A. Olech, Polym. Gels Ntwk. 4 (1996) 45.

[235] B. Krajewska, Polym. Gels Ntwk. 4 (1996) 55.

[236] B. Krajewska, React. Funct. Polym. 47 (2001) 37.

[237] H. Yoshida, A. Okamoto, H. Yamasaki, T. Kataoka (Eds.), Breakthrough curve for adsorption of acid dye on crosslinked chitosan fiber, in: Proceedings of the International Conference on Fundamentals of Adsorption, Kyoto, Japan, May 17-22, International Adsorption Society, 1992, 767-774.

[238] H. Yoshida, A. Okamoto, T. Kataoka, Chem. Eng. Sci. 48 (1993) 2267

[239] K. Inoue, K. Yoshizuka, K. Ohto, S. Seki, Kagaku Kogaku Ronbunshu 26 (2000) 548.

[240] K. Inoue, K. Yoshizuka, K. Ohto, H. Nakagawa, Chem. Lett. (2001) 698.

[241] T.C. Lo, M.H.I. Baird, C. Hanson, Handbook of Solvent Extraction, Krieger Publishing Company, Malabar, FL (U.S.A.), 1991, 980p.

[242] T.N. de Castro Dantas, A.A. Dantas Neto, M.C.P. de A. Moura, E.L. Barros Neto, E. de Paiva Telemaco, Langmuir 17 (2001) 4256.

[243] L. Fournel, R. Navarro, I. Saucedo, E. Guibal, in: V.S.T. Ciminelli, O. Garcia, Jr. (Eds.), Biohydrometallurgy: Fundamentals, Technology and Sustainable Development (IBS 2001), vol. 11B, Elsevier, Amsterdam, The Netherlands, 2001, pp. 109-118.

[244] W.S. Wan Ngah, I.M. Isa, J. Appl. Polym. Sci. 67 (1998) 1067.

[245] K. Inoue, in: M.G. Peter, A. Domard, R.A.A. Muzzarelli (Eds.), Advances in Chitin Chemistry, Vol. IV, University of Potsdam, Potsdam, Germany, 2000, 460-465.

[246] K. Inoue, K. Yoshizuka, K. Ohto, Anal. Chim. Acta 388 (1999) 209. 
[247] N. Ben-Shalom, in R. Brzezinski, I. Boucher, A. Retnakaran (Eds.), Chitosan-metal complex as a natural agricultural product against plant diseases, in: Proceedings of the 9th International Chitin-Chitosan Conference, Montréal, Canada, August 27-30, 2003.

[248] J. Xu, S.P. McCarthy, R.A. Gross, D.L. Kaplan, Macromolecules 29 (1996) 3436.

[249] H. Yamamoto, M. Amaike, Macromolecules 30 (1997) 3936.

[250] C. Peniche-Covas, W. Argüelles-Monal, J. San Roman, Polym. Degrad. Stab. 39 (1993) 21.

[251] M.A. Dubois, J.F. Dozol, C. Massiani, J. Anal. Appl. Pyrolysis 31 (1995) 129.

[252] F.A.A. Tirkistani, Polym. Degrad. Stab. 60 (1998) 67.

[253] K. Sreenivasan, Polym. Degrad. Stab. 52 (1996) 85.

[254] J.Z. Knaul, S.M. Hudson, K.A.M. Creber, J. Appl. Polym. Sci. 72 (1999) 1721.

[255] M.N.V. Ravi Kumar, React. Funct. Polym. 46 (2000) 1.

[256] L. Dambies, E. Guibal, A. Roze, Colloids Surf. A: Physicochem. Eng. Aspects 170 (2000) 19.

[257] L. Dambies, T. Vincent, E. Guibal, Water Res. 36 (2002) 3699.

[258] K. Yoshizuka, Z. Lou, K. Inoue, React. Funct. Polym. 44 (2000) 47.

[259] Q.-H. Shi, Y. Tian, X.-Y. Dong, S. Bai, Y. Sun, Biochem. Eng. J. 16 (2003) 317.

[260] E.B. Denkbas, E. Kiliçay, C. Birlikseven, E. Oztürk, React. Funct. Polym. 50 (2002) 225.

[261] I. Safarik, Water Research 29 (1995) 101.

[262] L. Cumbal, J.E. Greenleaf, D. Leun, A. SenGupta, React. Funct. Polym. 54 (2003) 167.

[263] M.J. DeMarco, A. SenGupta, J.E. Greenleaf, Wat. Res. 37 (2003) 164

[264] A. Drelinkiewicz, M. Hasik, J. Mol. Catal. A: Chem. 177 (2001) 149.

[265] B. Altava, M.I. Burguete, E. García-Verdugo, S.V. Luis, M.J. Vicent, J.A. Mayoral, React. Funct. Polym. 48 (2001) 125.

[266] G. Felix, J. Chromatogr. A. 906 (2001) 171.

[267] E. Yashima, J. Chromatogr. A. 906 (2001) 105.

[268] I. Malinowska, J.K. Rózyló, Biomed. Chromatogr. 11 (1997) 272.

[269] B.J. Arena, Chitin- and chitosan-based immobilized metal catalysts, US Patent 4,274,980 (June 23, 1981).

[270] B.J. Arena, Hydrogenation using chitin and chitosan based immobilized metal catalysts, US Patent 4,367,355 (January 4, 1983).
[271] B.J. Arena, Hydrogenation using chitin and chitosan based immobilized metal catalysts, US Patent 4,431,836 (February 14, 1984).

[272] E. Chiessi, B. Pispisa, J. Mol. Catal. 87 (1994) 177.

[273] N.V. Kramareva, A.Y. Stakheev, O. Tkachenko, K.V. Klementiev, W. Grünert, E. Finashina, L.M. Kustov, J. Mol. Catal. A: Chem. (2003), in press.

[274] A.V. Kucherov, N.V. Kramareva, E. Finashina, A.E. Koklin, L.M. Kustov, J. Mol. Catal. A: Chem. 198 (2003) 377.

[275] X. Zeng, Y. Zhang, Z. Shen, J. Polym. Sci. A. Polym. Chem. 35 (1997) 2177.

[276] F. Quignard, A. Choplin, A. Domard, Langmuir 16 (2000) 9106.

[277] F. Quignard, Austr. J. Chem. 55 (2002) 73.

[278] H. Wang, W. Sun, C. Xia, J. Mol. Catal. A: Chem. 206 (2003) 199.

[279] J. Zhang, C.-G. Xia, J. Mol. Catal. A: Chem. 206 (2003) 59.

[280] J.-J. Jin, G.-C. Chen, M.-Y. Huang, Y.-Y. Jiang, React. Polym. 23 (1994) 95.

[281] H.-S. Han, S.-N. Jiang, M.-Y. Huang, Y.-Y. Jiang, Polym. Adv. Technol. 7 (1996) 704.

[282] M.-Y. Yin, G.-L. Yuan, Y.-Q. Wu, M.-Y. Huang, Y.-Y. Jiang, J. Mol. Catal. A: Chem. 147 (1999) 93.

[283] T. Vincent, E. Guibal, Ind. Eng. Chem. Res. 41 (2002) 5158.

[284] T. Vincent, S. Spinelli, E. Guibal, Ind. Eng. Chem. Res. 42 (2003) 5968.

[285] T. Vincent, E. Guibal, Langmuir 19 (2003) 8475.

[286] T. Vincent, E. Guibal, Adv. Environ. Res. (2003), in press.

[287] K. Esumi, N. Takei, T. Yoshimura, Colloids Surf. B: Biointerf. 32 (2003) 117.

[288] D.D. Hu, Q.Z. Shi, Z.X. Tang, Y. Fang, J.F. Kennedy, Carbohydr. Polym. 45 (2001) 385.

[289] E. Guibal, T. Vincent, Environ. Sci. Technol. (2003), in press.

[290] N.S. Mohamed, R.H.Y. Subban, A.K. Arof, J. Power Sources 56 (1995) 153.

[291] M.Z.A. Yahya, A.K. Arof, Eur. Polym. J. 38 (2002) 1191.

[292] M.Z.A. Yahya, A.K. Arof, Eur. Polym. J. 39 (2003) 897.

[293] X. Ye, Q. Yang, Y. Wang, N. Li, Talanta 47 (1998) 1099.

[294] H. Jiang, W. Su, S. Caracci, T.J. Bunning, T. Cooper, W.W. Adams, J. Appl. Polym. Sci. 61 (1996) 1163.

[295] Y. Yonezawa, T. Sato, I. Kawabata, Chem. Lett., (1994) 355.

[296] Y. Yonezawa, I. Kawabata, T. Sato, Ber. Bunsenges. Phys. Chem. 100 (1996) 39.

[297] X.-P. Wang, Z.-Q. Shen, Polym. Int. 49 (2000) 1426.

[298] N. Kubota, J. Appl. Polym. Sci. 64 (1997) 819. 